\title{
On Multidecadal and Quasi-Decadal North Atlantic Variability
}

\author{
F. Álvarez-García \\ Departamento de Física, Universidad de Alcalá, Alalá de Henares, Madrid, Spain \\ M. LATIF AND A. BIASTOCH \\ Leibniz-Institut für Meereswissenschaften, Kiel, Germany
}

(Manuscript received 4 December 2006, in final form 31 October 2007)

\section{ABSTRACT}

\begin{abstract}
Observed sea surface temperatures (SSTs) in the North Atlantic from 1958 through 2000, as well as data from an ocean model simulation driven with the atmospheric variability observed during the same period, are examined using multichannel singular spectrum analysis. The two leading oscillatory modes are associated with a multidecadal and a quasi-decadal period. The former is connected to a basinwide uniform SST pattern and changes in the deep North Atlantic meridional overturning circulation. The quasi-decadal mode involves a tripolar SST anomaly pattern forced by atmospheric variability with a spatial structure resembling that of the North Atlantic Oscillation (NAO). The upper ocean's dynamical response to this NAO variability provides an instantaneous positive feedback to the SST pattern, while a delayed negative feedback is due to shallow overturning circulation anomalies.
\end{abstract}

\section{Introduction}

Observational studies have revealed considerable decadal and multidecadal variability in the surface climate of the North Atlantic Ocean (Deser and Blackmon 1993; Kushnir 1994; Czaja and Marshall 2001). The potential predictability associated with such low-frequency fluctuations as well as their possible modification by the expected anthropogenic climate change have motivated recent efforts to understand the physical mechanisms responsible for these variations.

On the multidecadal time scales, an interhemispheric dipolar SST pattern, with the North and the South Atlantic in phase opposition, has been connected to changes in the thermohaline circulation (THC) in modeling studies (Latif et al. 2004, 2006b; Knight et al. 2005, 2006). Whether these multidecadal THC changes originate exclusively in the ocean or whether atmosphereocean coupling plays an important role remains an open question. The multidecadal variability in the North Atlantic SST has strong impacts on the climates of the adjacent landmasses (Sutton and Hodson 2005). It has also been linked, for instance, to variations in Sahelian rainfall and Atlantic sector hurricane activity (Knight et al. 2006; Zhang and Delworth 2006).

Corresponding author address: F. Álvarez-García, Departamento de Física, Universidad de Alcalá, 28871 Alcalá de Henares, Madrid, Spain.

E-mail: franciscoj.alvarez@uah.es
On shorter time scales of about a decade, the characteristic SST pattern is tripolar, with centers of actions in the western midlatitudinal Atlantic, the subpolar region, and the tropics. This structure strongly projects on the SST tripole, which is forced by the North Atlantic Oscillation (NAO; Cayan 1992); a recent review of the ocean's response to the NAO can be found in Visbeck et al. (2003). Several mechanisms have been proposed to explain this decadal variability. Atmospheric stochastic forcing may set a dominant decadal time scale in the ocean through the excitation of long baroclinic Rossby waves (Frankignoul et al. 1997). Alternatively, spatially coherent atmospheric forcing can interact with the oceanic mean flow advection and lead to the preferred decadal time scale through spatial resonance (Saravanan and McWilliams 1998). Support for the role of the mean circulation has been provided by observations of SST anomalies propagating along the paths of the Gulf Stream and the North Atlantic Current (Hansen and Bezdek 1996; Sutton and Allen 1997), which have also been found in ocean modeling studies (Krahmann et al. 2001). While such stochastic mechanisms result from a rather simple representation of ocean-atmosphere interaction, analyses of simulations with coupled atmosphere-ocean general circulation models (CGCMs) indicate the possibility for coupled decadal oscillations (Grötzner et al. 1998; Wu and Liu 2005). Their existence would rely on the delayed adjustment of the ocean gyres to anomalous wind stress 
forcing, and on the atmospheric response to the SST anomalies produced by the adjustment. The characteristics of this response and whether it actually occurs in nature are currently under debate. An additional coupled mechanism has been proposed in which oceanic gyre circulation provides a positive feedback via its instantaneous barotropic adjustment to wind stress anomalies (Eden and Greatbatch 2003, hereafter EG03). The delayed negative feedback for the oscillation is introduced by anomalies of the THC.

The present work reports the results of an analysis of an ocean model simulation driven with observed atmospheric variability. In addition to the multidecadal variability, a realistic quasi-decadal oscillation is detected in the model SST. The underlying mechanism appears to be consistent with the framework of instantaneous gyre adjustment-delayed THC response described by EG03.

\section{Data and methodology}

We analyze data from a global ocean simulation forced by observed atmospheric variability during 1958-2000. The model is based on the latest version 9 [Nucleus for European Modelling of the Ocean (NEMO)] of the French Océan Parallélisé (OPA) model (Madec et al. 1999), including a dynamicthermodynamic sea ice model and state-of-the-art numerics as advanced advection schemes and partial cells (for an overview on the effects see Barnier et al. 2005). The global setup with a tripolar grid has a nominal resolution of $0.5^{\circ}$ (ORCA05). The eddy parameterization after Gent and McWilliams (1990) is used since the model does not permit mesoscale eddies. The resolution, however, is sufficient to resolve western boundary current structures and frontal regimes. In the vertical, the water column is divided in 46 nonequidistant levels, with grid cells ranging from $6 \mathrm{~m}$ at the surface to $250 \mathrm{~m}$ at depth. The bottom cells are allowed to be partially filled, resulting in a more precise bottom gradient representation than in traditional $z$-coordinate models. Vertical eddy viscosity and diffusivity coefficients are presented by a 1.5 -order closure model; static instabilities are removed by increasing these coefficients. At the surface, a consistent daily interannually varying forcing is applied for momentum, heat, and freshwater fluxes [Common Ocean Reference Experiments (CORE) by Large and Yeager (2004)]. The fields are applied via bulk formulas, allowing some feedback of the ocean on the total fluxes. A marked sensitivity of the meridional overturning circulation (MOC) to the details of the polar freshwater budget was noticed during the climatological spinup stage. A $10 \%$ reduction in precipitation, one of the atmospheric fields with the largest uncer- tainty, leads to stable MOC behavior. However, in this experiment we kept the original CORE fields and rather chose to apply a weak restoring (time scale 180 days) of temperature and salinity toward climatological values throughout the whole water column (outside the polar regions only surface salinity restoring is applied) to minimize the drift of the MOC. This gives a somewhat robust diagnostic polar circulation but keeps the surface forcing variability (Biastoch et al. 2008).

To gain insight into the details of the decadal-scale variability we have included several fields in our statistical analysis: surface wind stress and net heat flux, SST, temperature averaged over the upper $300 \mathrm{~m}$, and horizontal currents averaged over the upper $100 \mathrm{~m}$. All variables have been interpolated from the model's irregular grid onto a regular $1^{\circ} \times 1^{\circ}$ grid extending over the Atlantic basin north of the equator. We also include in our analysis the MOC in the Atlantic as represented by the meridional streamfunction, again north of the equator. We use in all cases annual anomalies of ocean data computed with respect to the mean of the simulated period (1958-2000).

For comparison, we make use of the observed SST from the Hadley Centre's Sea Ice and SST dataset version 1.1 (HadISST1.1; Rayner et al. 2003). It supplies data for the period $1870-2004$ on a $1^{\circ} \times 1^{\circ}$ grid. We consider both the entire 1870-2004 period and the shorter subperiod from 1958 through 2000, which overlaps with the simulated period. Annual anomalies for each period are taken about the respective means. The simulated SST variance agrees well with the observations with respect to both spatial distribution and magnitude. The correlation between modeled and observed SSTs amounts to values of more than 0.7 for the vast majority of the Atlantic.

We use multichannel singular spectrum analysis (MSSA) to extract the dominant spatiotemporal patterns of our data. For a deeper and more technical description of MSSA than is given below, the reader is referred to Ghil et al. (2002). One of the numerous examples of its use in climate studies is the work of Moron et al. (1998), who applied it to SST data in different regions, among them the North Atlantic Ocean.

MSSA extends classical principal components analysis (PCA) by considering not only simultaneous but also lagged relationships between time series from several input channels. A lag-covariance matrix, of size determined by the number of channels and the chosen lag-window width, is diagonalized, yielding eigenvectors, or space-time empirical orthogonal functions (STEOFs), that consist of lag sequences of maps. Spacetime principal components (ST-PCs) are obtained from 
projection of the data onto the ST-EOFs. An important property of MSSA is its ability to detect modulated oscillations in the data, indicated by pairs of ST-EOFs that explain similar amounts of variance and are in phase quadrature (and so are, in consequence, the corresponding ST-PCs).

It must be noted, however, that the appearance of one of these ST-EOF pairs is not a conclusive argument for the presence of an oscillation. They can also arise from finite samples of some nonoscillatory processes, such as first-order autoregressive (AR1) noise. It is thus advisable to test possible oscillatory MSSA modes identified in a climate dataset against the red noise hypothesis, before any further discussion of their features. In this work, we follow the procedure designed by Allen and Robertson (1996): as a first step, the time series from the different input channels are used to compute the parameters of as many AR1 processes. Realizations of independent AR1 noise processes can now be generated for each channel. A large ensemble is created with the purpose of calculating, through projection of the noise lag-covariance matrices on the data eigenfunctions, confidence intervals for the eigenvalues under the null hypothesis of red noise. An additional and more conservative alternative employs the AR1 noise rather than the data eigenfunctions. The projection of the data lag-covariance matrix on them allows us, after estimating the corresponding confidence intervals, to examine whether more variance than expected under the red noise null hypothesis occurs at a given time scale (determined by the eigenfunction's dominant frequency).

Classical PCA is used to reduce data dimensionality, keeping $90 \%$ of the variance in the PCs that enter MSSA. In the case of the simulated data, $90 \%$ of variance is retained for each of the variables listed above, and a joint MSSA is performed including all of those fields in the input. At a later stage in the analysis, an additional MSSA is carried out on the zonal wind stress data only.

The MSSA is repeated using different lag windows of $15,20,25$, and $30 \mathrm{yr}$ to test the robustness of the results. The results are very stable. A lag of $25 \mathrm{yr}$ is used in the following for the analysis of the 1870-2004 data, and of $15 \mathrm{yr}$ for the 1958-2000 data. We perform the significance tests of Allen and Robertson (1996) on the longer dataset.

\section{Results}

\section{a. Observed SST 1870-2004}

MSSA was performed for the region $0^{\circ}-75^{\circ} \mathrm{N}$. Figure 1 shows the MSSA variance spectrum of the annual SST anomalies observed from 1870 through 2004. The

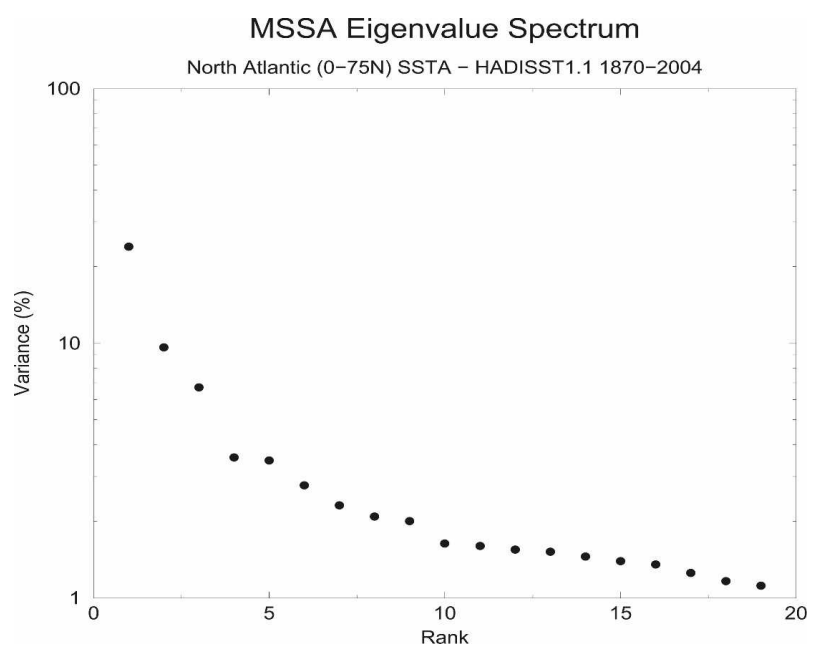

FIG. 1. MSSA eigenvalue spectrum of the observed annual SST anomalies (from HadISST1.1 1870-2004).

most energetic mode, with about $25 \%$ of the total variance, essentially accounts for the warming of the North Atlantic Ocean between the 1910s and the 1940s, as shown in the reconstruction of the basinwide $\left(0^{\circ}-75^{\circ} \mathrm{N}\right.$, $80^{\circ}-10^{\circ} \mathrm{W}$ ) average SST anomaly (Fig. 2). The zero-lag regression of the North Atlantic SST anomalies on this reconstruction (not shown) largely reproduces the observed twentieth-century trend pattern reported in other works (Karoly and Wu 2005), including cooling between $50^{\circ} \mathrm{N}$ and Greenland, west of $20^{\circ} \mathrm{W}$. For comparison with the planetary warming trend, the globally averaged SST anomaly (smoothed with a 21-yrrunning-mean filter) is plotted alongside the reconstruction of the North Atlantic average in Fig. 2. As stated above, the 1910-50 warming is well captured in the latter, but the trend since around 1970 is absent. The North Atlantic average also exhibits some multidecadal variability, so a complete separation of the multidecadal and climate change signals cannot be attained in our analysis. The problem is aggravated for shorter lag windows and consequently lower spectral resolution.

The second and third MSSA eigenvalues, which account altogether for $17 \%$ of the variance, have a dominant multidecadal time scale and the corresponding ST-PCs bear the phase-quadrature relationship characteristic of oscillatory pairs. Their reconstruction of the North Atlantic basin-average SST anomaly (Fig. 3) yields a time series that is basically equivalent to the Atlantic Multidecadal Oscillation (AMO) index given by Knight et al. (2005) or Sutton and Hodson (2005). The zero-lag regression map (Fig. 4) is also consistent with these and previous studies (Kushnir 1994; Latif et al. 2004). The multidecadal variability is associated with 


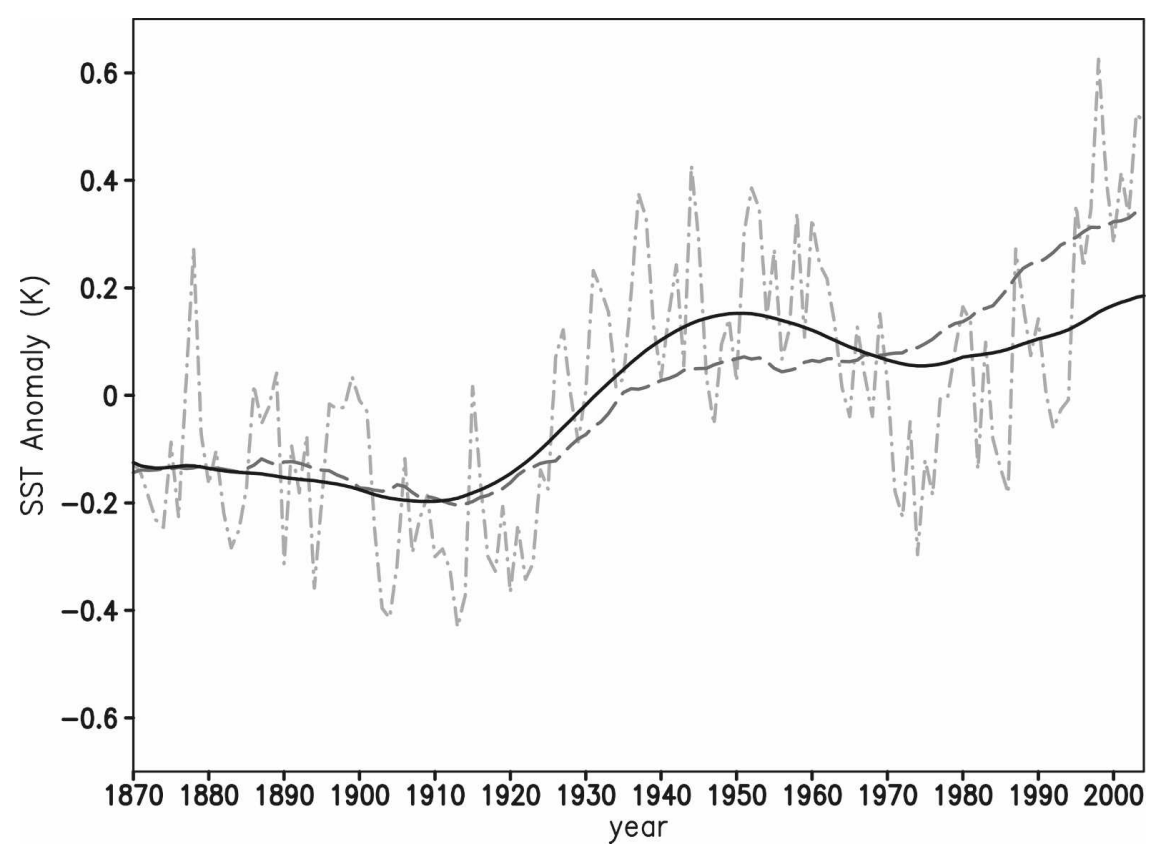

FIG. 2. North Atlantic basinwide $\left(0^{\circ}-75^{\circ} \mathrm{N}, 80^{\circ}-10^{\circ} \mathrm{W}\right)$ average SST anomaly (light gray, dot-dashed); reconstruction with MSSA component 1 (black, solid); and globally averaged SST anomaly, smoothed with a 21-yr-running-mean filter (dark gray, dashed).

a uniform spatial pattern such that SST anomalies of the same sign extend over most of the North Atlantic basin. Strongest anomalies occur in the western midlatitude and in the subpolar North Atlantic. The lagged-regression analysis shown in Fig. 4 suggests the pattern is not stationary: anomalies of one sign off the American coast around $40^{\circ} \mathrm{N}$ (appearing, e.g., at lag -20$)$ precede anomalies of the same sign south of

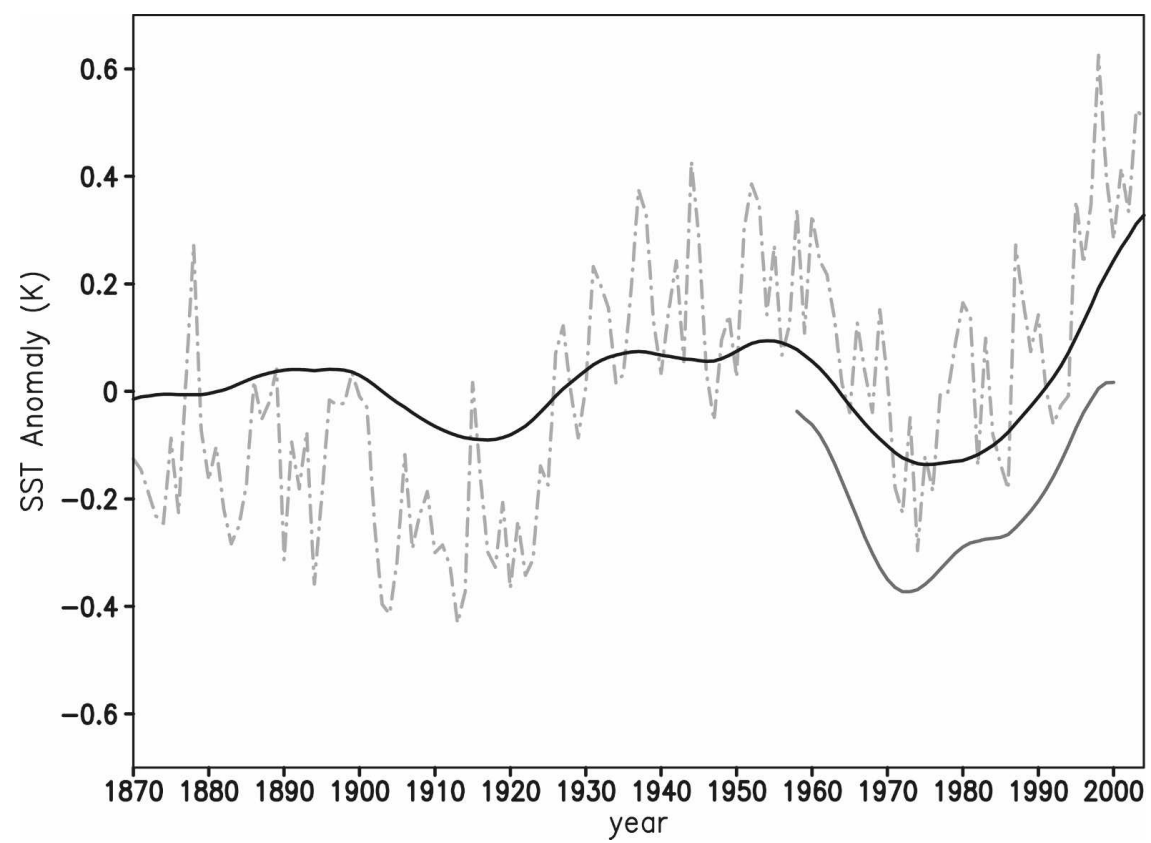

FIG. 3. North Atlantic basinwide $\left(0^{\circ}-75^{\circ} \mathrm{N}, 80^{\circ}-10^{\circ} \mathrm{W}\right)$ average SST anomaly (light gray, dot-dashed); reconstruction with components 2 and 3 from MSSA on the 1870-2004 North Atlantic SST anomalies (black, solid); and reconstruction with components 1 and 2 from MSSA on the 1958-2000 North Atlantic SST anomalies (dark gray, solid; offset -0.2). 

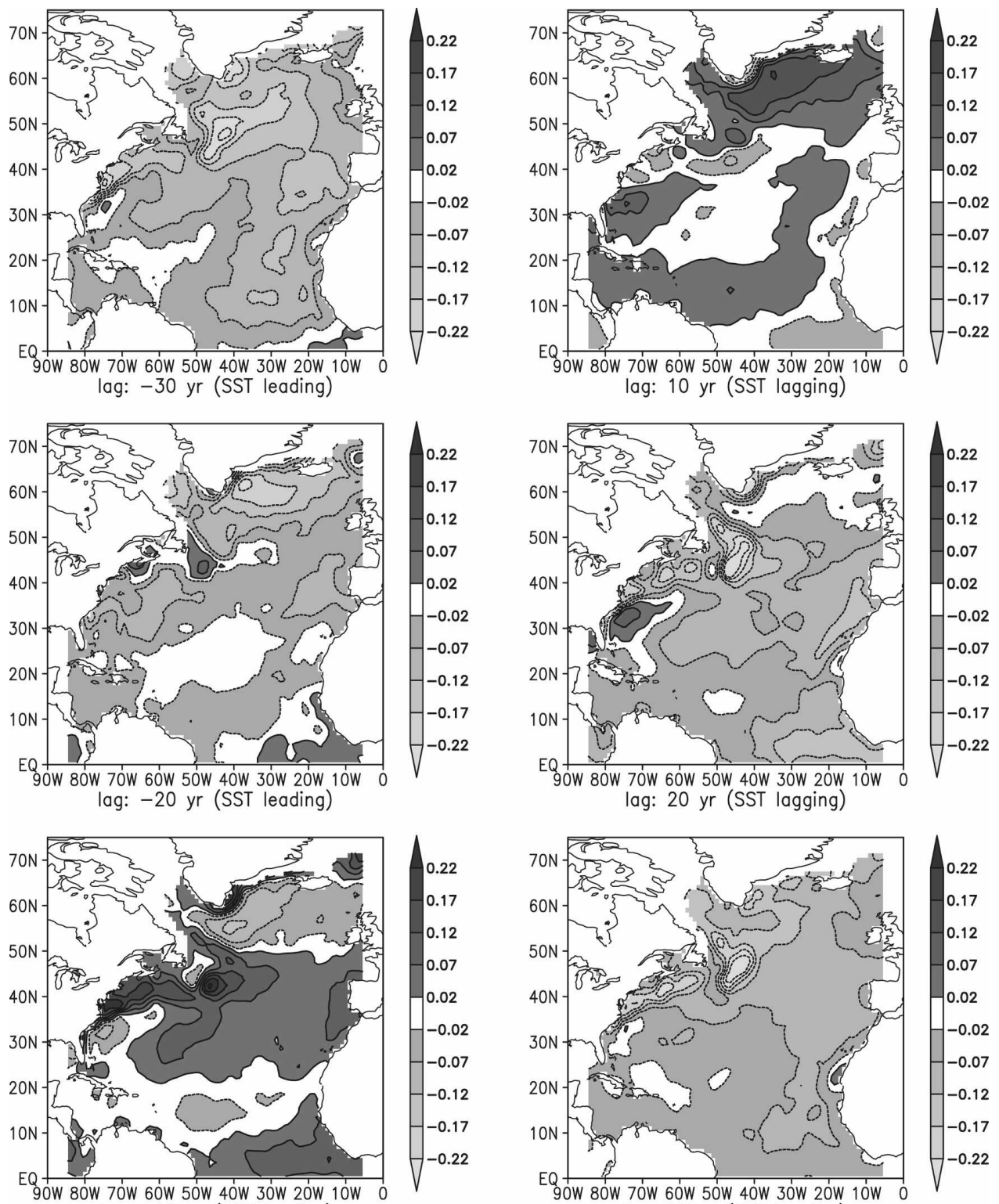
lag: $-10 \mathrm{yr}$ (SST leading)

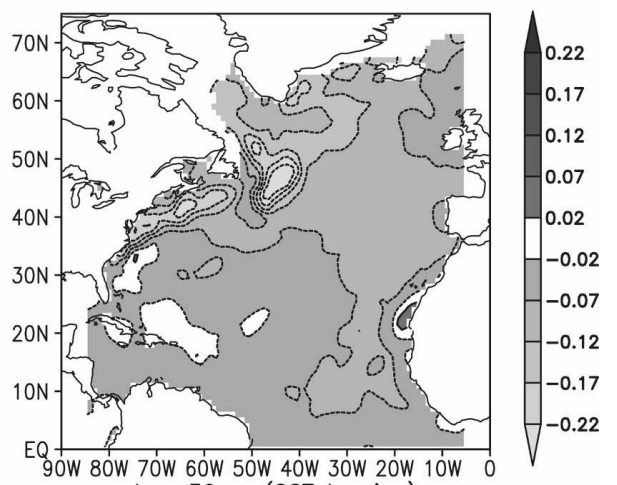
lag: 30 yr (SST lagging)
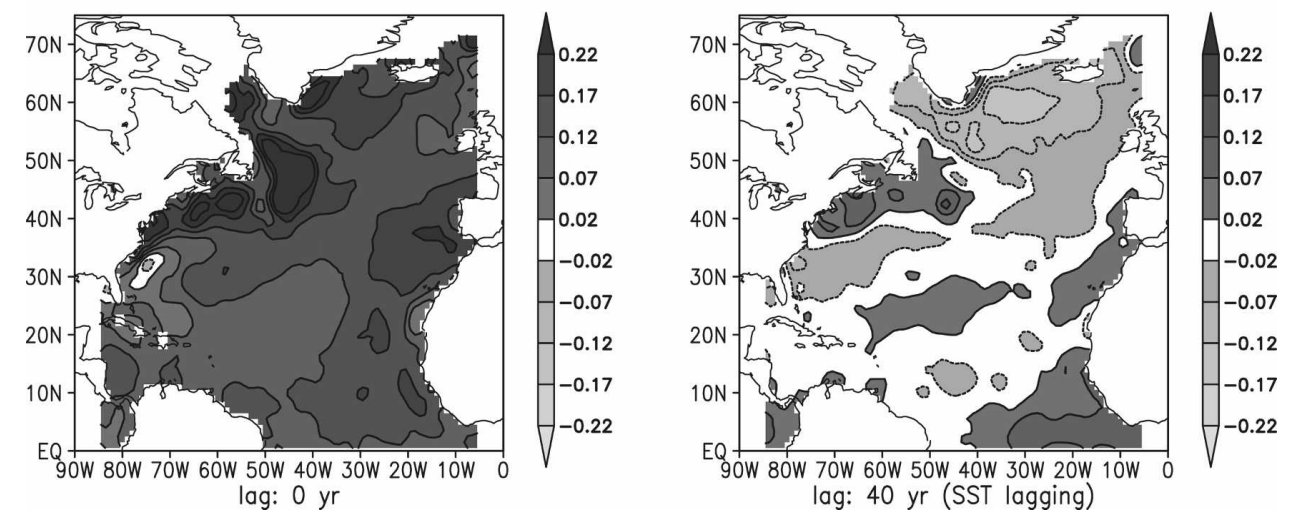

FIG. 4. Lagged regression of SST anomaly (SSTA; from HadISST1.1 1870-2004) on the multidecadal reconstruction of the North Atlantic basin-average SST anomaly. Units are ${ }^{\circ} \mathrm{C}$ per standard deviation of the latter time series. 

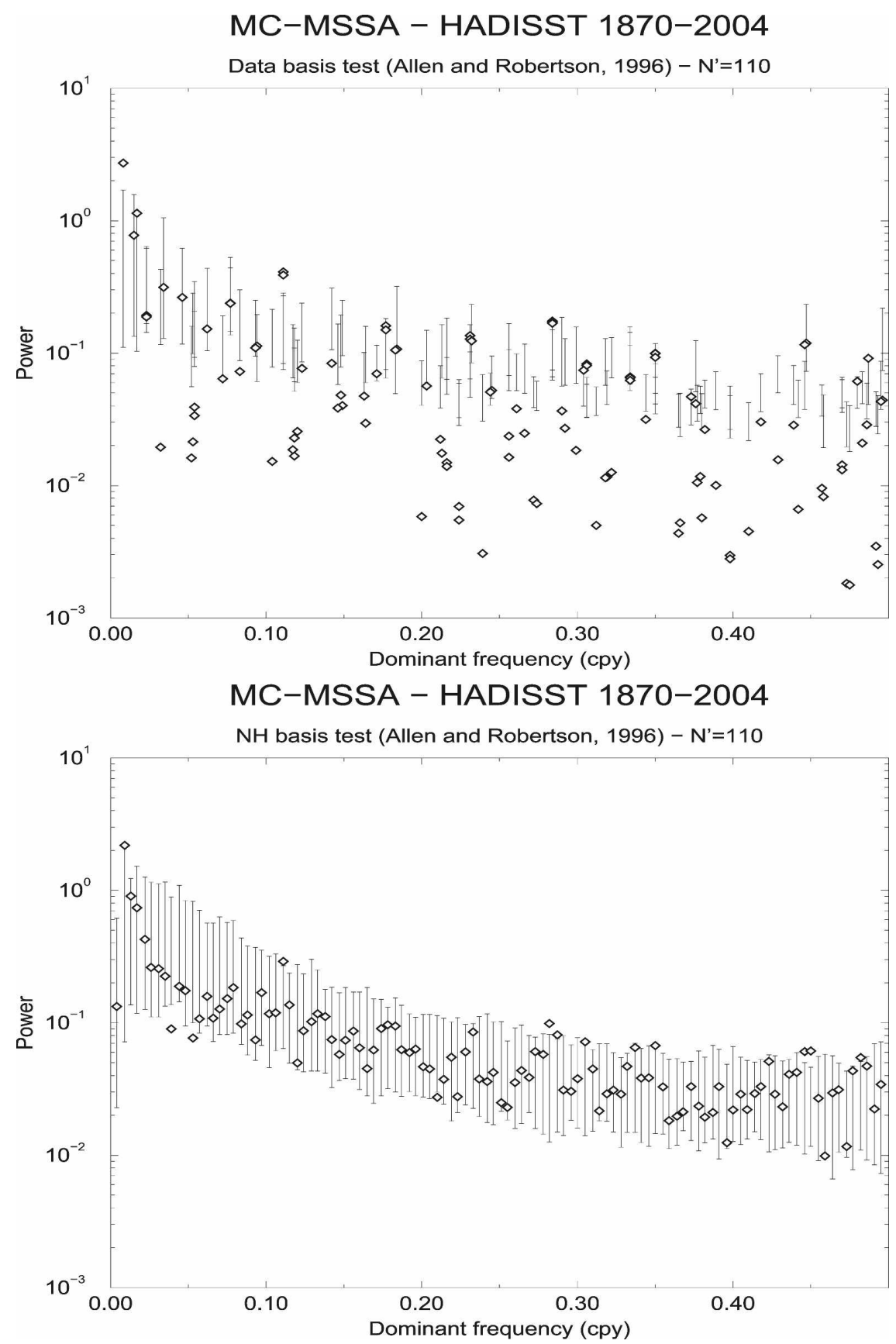

FIG. 5. Monte Carlo MSSA tests (Allen and Robertson 1996) for the observed annual SST anomalies (from HadISST1.1 1870-2004). (top) Test using the data-adaptive basis; (bottom) test using the null-hypothesis (red noise) basis. In both (top) and (bottom), the diamonds represent the projection of the data lag-covariance matrix on the basis eigenfunctions. The vertical bars indicate the $95 \%$ confidence interval for the projection under the red noise null hypothesis. They are derived from a sample of 100 realizations of a red noise process fitted to the data.

Iceland (lag 0) by about $20 \mathrm{yr}$, hinting at a connection with the propagation of SST anomalies along the North Atlantic Current detected by Sutton and Allen (1997). This issue receives further attention below.
North Atlantic multidecadal variability with the structure described above is shown to be related to changes in the meridional heat transport by the THC in the CGCM simulations analyzed by Latif et al. (2004) 


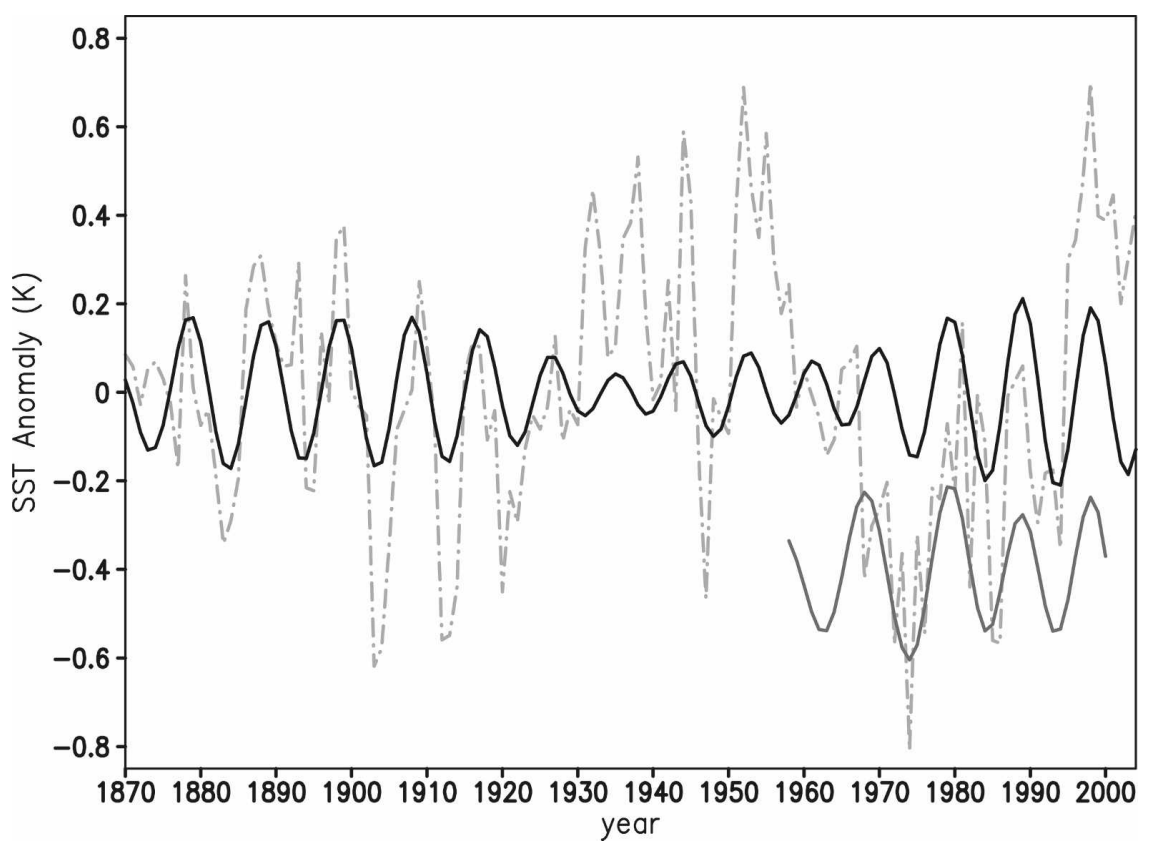

FIG. 6. SST anomalies averaged over $\left(40^{\circ}-60^{\circ} \mathrm{N}, 50^{\circ}-10^{\circ} \mathrm{W}\right.$; light gray, dot-dashed), reconstruction with components 4 and 5 from MSSA on the 1870-2004 North Atlantic SST anomalies (black, solid), and reconstruction with components 3 and 4 from MSSA on the 1958-2000 North Atlantic SST anomalies (dark gray, solid; offset -0.4).

and Knight et al. (2005). Caution must attend the interpretation of our results, however, given the difficulties in discriminating the multidecadal and the climate change signals. It was indicated above that a minor part of the multidecadal variability is included in the first MSSA component. In addition, this component does not reproduce the global warming trend during the last decades of the twentieth century, which is thus likely to affect the reconstruction of multidecadal variability, as already noted by Trenberth and Shea (2006). Despite this, the similarities between the results presented here and those derived from control CGCM experiments afford confidence in a generally correct identification of the multidecadal signal.

The fourth and fifth eigenvalues in the variance spectrum of Fig. 1 form an oscillatory pair with a period of roughly $9 \mathrm{yr}$, explaining 7\% of the SST variance. This pair passes the Monte Carlo MSSA tests of Allen and Robertson (1996) against red noise at the 95\% significance level, as illustrated in Fig. 5. The projection of the data lag-covariance matrix on the data-adaptive basis (Fig. 5, top) and on the red noise null-hypothesis basis (Fig. 5, bottom) both indicate an improbably high variance at the quasi-decadal time scale, relative to what would be expected under the red noise assumption. This is supportive of the actual presence of a quasidecadal oscillation in the data, captured by the MSSA oscillatory pair. Notice that the multidecadal eigenvalues (ranking second and third in power) do not attain statistical significance over red noise at the level fixed in the tests. This, however, was expected given the relatively short record length.

The reconstructed SST anomalies for the oscillatory pair display quasi-decadal fluctuations with a multidecadal modulation of their amplitude over the observed record (Fig. 6). The spatial structure of the oscillation is characterized by anomalies of one sign in the western midlatitudes and anomalies of opposite sign arranged in a horseshoe pattern with local maxima in the subpolar and tropical areas (Fig. 7). Both the pattern and the amplitude modulation are consistent with the results from other investigations of North Atlantic decadal variability (Moron et al. 1998; Deser and Blackmon 1993). The spatial pattern resembles the SST tripole associated with the NAO on interannual time scales. The oscillation is essentially stationary, and does not appear to involve advection of SST anomalies by the mean North Atlantic currents, one mechanism proposed in previous works (Saravanan and McWilliams 1998) to explain decadal variability in the North Atlantic.

The covariability of the tripole SST pattern and the NAO has been shown to vary on multidecadal time scales by Walter and Graf (2002). Their correlation 

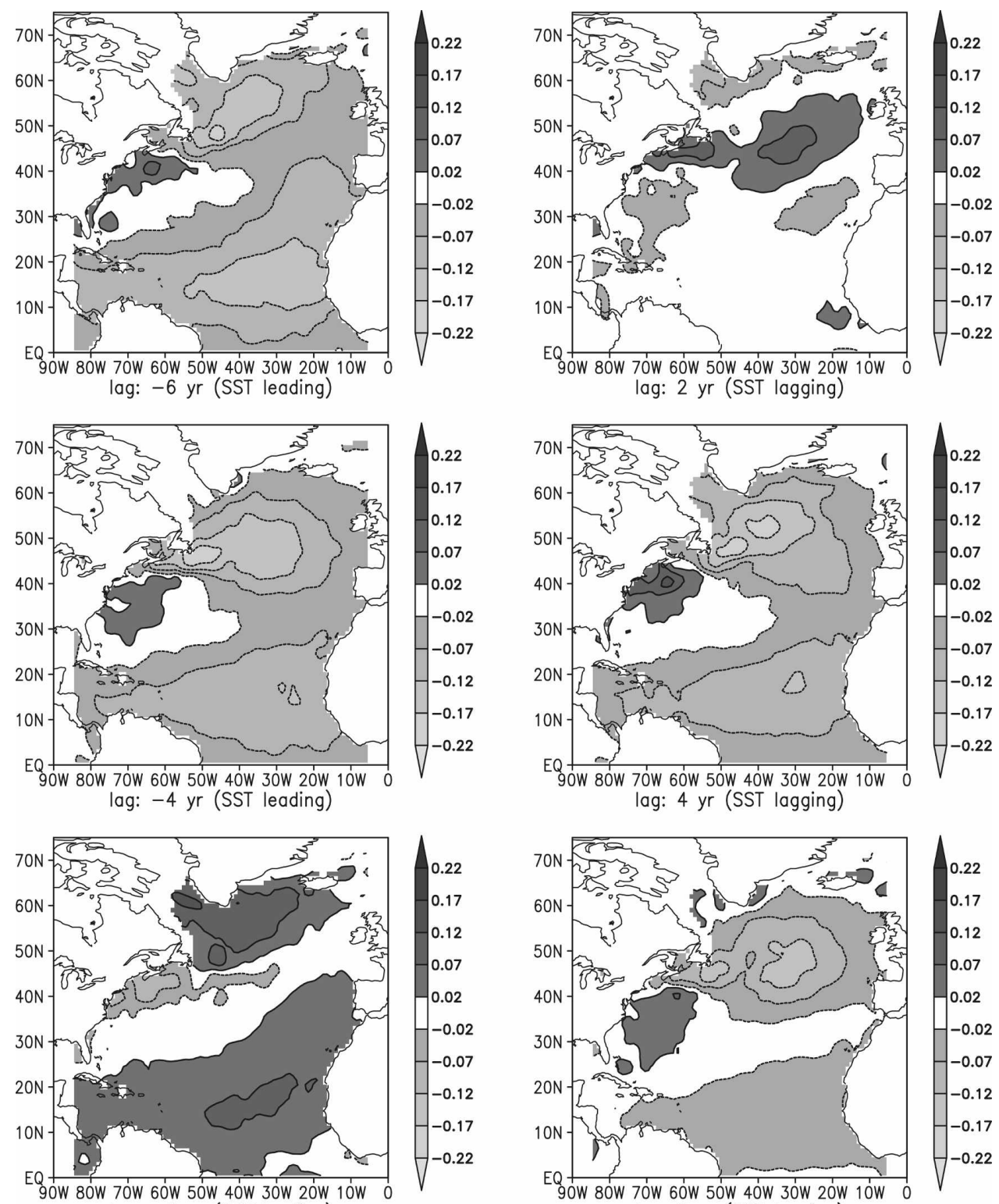
lag: -2 yr (SST leading)

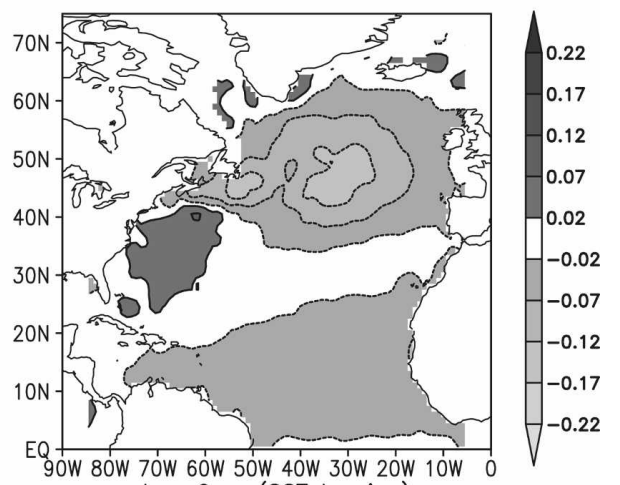
lag: 6 yr (SST lagging)
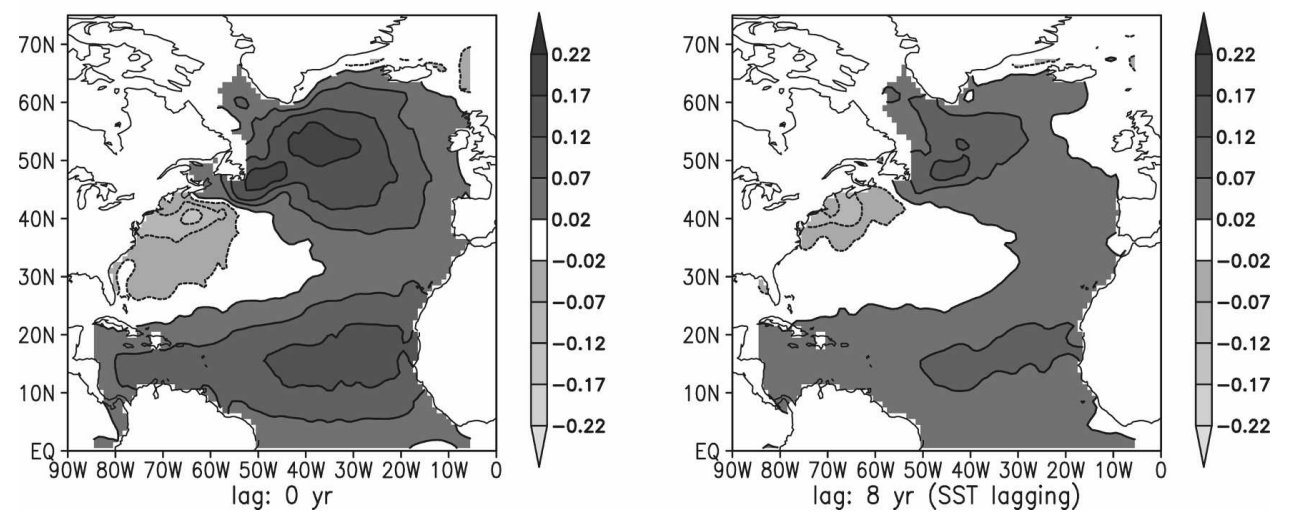

FIG. 7. Lagged regression of SSTA (from HadISST1.1 1870-2004) on the quasi-decadal reconstruction of SST anomalies averaged over $\left(40^{\circ}-60^{\circ} \mathrm{N}, 50^{\circ}-10^{\circ} \mathrm{W}\right)$. Units are ${ }^{\circ} \mathrm{C}$ per standard deviation of the latter time series. 
weakens from the 1930s to the early 1960s, and increases during the last decades of the century. As noted by Walter and Graf (2002), these periods correspond respectively to a warm and a cold phase of the multidecadal variability. During the latter, the NAO was characterized by enhanced variability on the quasidecadal time scale, matching the amplitude modulation of the quasi-decadal SST oscillation in Fig. 6. Walter and Graf (2002) also find that remote influences from the tropical Pacific are more important during the period of lower correlation and weaker quasi-decadal variability. The origin of the amplitude modulation of the quasi-decadal mode is not pursued further in the present study.

The propagation characteristics of the two modes were studied next. We focus on the period 1958-2000, which includes a full cold phase of the multidecadal signal and exhibits pronounced quasi-decadal variability. MSSA was performed on North Atlantic SSTs on a horizontal $1^{\circ} \times 1^{\circ}$ grid in the region $0^{\circ}-75^{\circ} \mathrm{N}$. Classical PCA is used again to reduce data dimensionality, keeping $90 \%$ of the variance in the PCs that enter MSSA. The first two eigenvalues are related to the multidecadal variability and the next pair of eigenvalues to the quasi-decadal oscillation. Their correspondence with the modes detected in the 1870-2004 analysis is illustrated in the reconstruction of the indices in Figs. 3 and 6. Further comparison of the multidecadal and quasidecadal MSSA modes is given in Fig. 8, which attempts to illustrate how they contribute to the propagation of SST anomalies along a path approximating that of Sutton and Allen (1997) shown in Fig. 8a. Slow propagation from the western subtropics into the eastern subpolar Atlantic occurs on the multidecadal time scale (Fig. 8b). In contrast to this, the quasi-decadal oscillation is mostly stationary (Fig. 8c). Thus, the quasidecadal mode appears to be unrelated to the mean advection of SST anomalies by the North Atlantic Current, as will be described below by discussing the results of our ocean model simulation.

In the following section we use the extensive dataset from the forced ocean simulation to investigate the physics behind the decadal oscillation detected in the observations.

\section{b. ORCA05 simulation 1958-2000}

The joint MSSA analysis of the oceanic fields selected from the ORCA05 simulation of the 1958-2000 period yields again a multidecadal and a quasi-decadal oscillatory mode as the two leading modes. The eigenvalue spectrum is not shown.

We discuss first the simulated multidecadal mode (Figs. 9-11). We display snapshots $5 \mathrm{yr}$ apart from each other, as reconstructed from the multidecadal mode. The prolonged negative SST anomaly of 1970-80 (Fig. 9), as reconstructed from the multidecadal mode, covers the whole North Atlantic and is therefore a negative phase of the multidecadal cycle. The model emphasizes the multidecadal variability in the subpolar region and underestimates it in the central and western tropical North Atlantic. Despite these deviations, a good reproduction of the observed multidecadal mode is obtained.

The cold SST anomalies are preceded by a basinwide cell of negative anomalies in the meridional streamfunction, and thus by a weaker overturning about $5 \mathrm{yr}$ before (Fig. 10). The anomalously weak overturning is a result of an anomalously weak NAO and the associated reduced heat loss of the ocean to the atmosphere in the Labrador Sea at this time (Fig. 11). The snapshots of the model's overturning streamfunction $5 \mathrm{yr}$ apart from each other, as reconstructed from the multidecadal mode (Fig. 10), show clearly how the negative overturning anomalies develop in the 1960s and subsequently slowly propagate southward. During 1970-80, the height of the cold phase in surface temperature, the tendency in the streamfunction is reversed and the negative anomalies start to weaken until they are replaced by positive overturning anomalies in the mid1980s in the north. The positive anomalies expand southward and initiate the subsequent warm phase in the 1990s, which is characterized by an anomalously strong MOC. The anomalous surface currents show clearly either a reduced or strengthened North Atlantic Current during the extreme cold and warm phases, respectively (Fig. 9). Thus, we expect some propagation of SST anomalies along the path of the North Atlantic Current for the multidecadal mode.

By and large the results for the simulated multidecadal mode are consistent with those of Eden and Jung (2001) and Eden and Willebrand (2001), who describe the response of the MOC to variations in the NAO and the associated surface heat flux variations over the Labrador Sea by means of ocean model simulations. The results for the multidecadal mode derived from our forced ocean model simulation are also consistent with those of Latif et al. (2006b), who show that a proxy of the MOC derived from Atlantic SSTs exhibits a consistent phase relationship with the NAO on decadal time scales, with the NAO leading by approximately a decade.

Next, we study the simulated quasi-decadal mode. We reconstruct the annual anomalies of the different fields retaining this variability, and compute phase composites following the procedure described in Moron et al. (1998) to study the features of the decadal mode. Figure 12 shows that the simulated decadal os- 

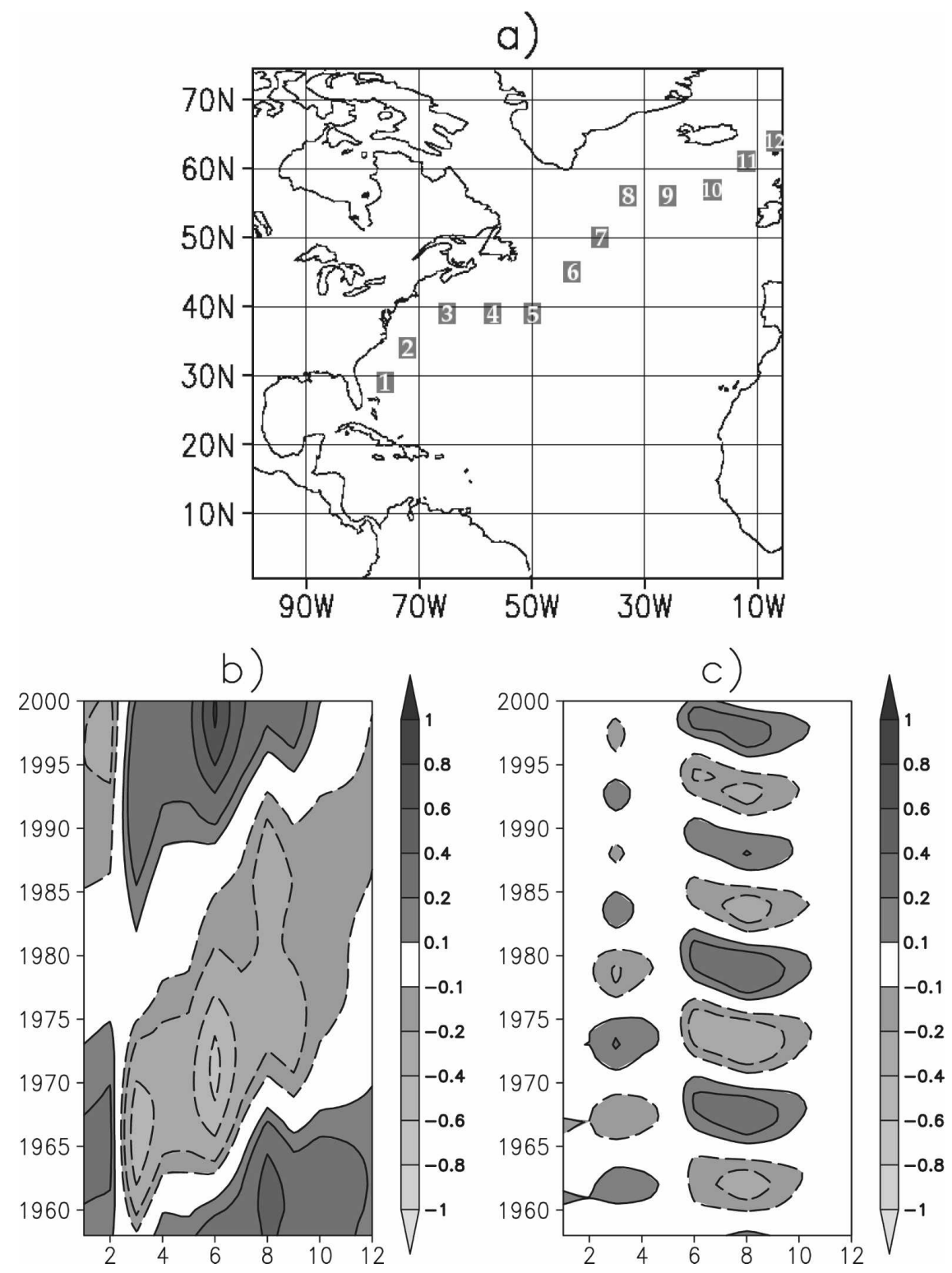

FIG. 8. (a) Path for the SST anomalies diagrams (b) and (c). SST anomalies (K) are averaged over the $3^{\circ} \times 3^{\circ}$ boxes, numbered in the diagrams starting at the easternmost position. (b) Reconstructed 1958-2000 SST anomalies associated with the MSSA multidecadal mode. (c) Reconstructed 1958-2000 SST anomalies associated with the MSSA decadal mode.

cillation has the same horseshoe anomaly structure in the SST, straddling anomalies of opposite sign off the coast of the United States, as the observed decadal mode (Fig. 7). The pattern emerges more clearly in the simulation, in agreement with the increase in the amplitude of the decadal oscillation during the second half of the twentieth century (Fig. 6). It is seen in Fig. 12 that SST anomalies off the south coast of Greenland and in the Labrador Sea (phases 4 and 8) lead the change of phase and precede the fully developed horseshoe pat- tern (phases 6 and 2) by about 2 yr. This feature is rather faint and barely noticeable in the observed oscillation. Deser and Blackmon (1993) find a similar lagged relationship in the observations between sea ice extent anomalies in the Davis Strait and Labrador Sea, and an SST structure reminiscent of our decadal pattern and with approximately the same time scale.

The wind stress anomalies associated with the decadal SST oscillation are illustrated in Fig. 13. The development of a positive (negative) horseshoe anomaly 

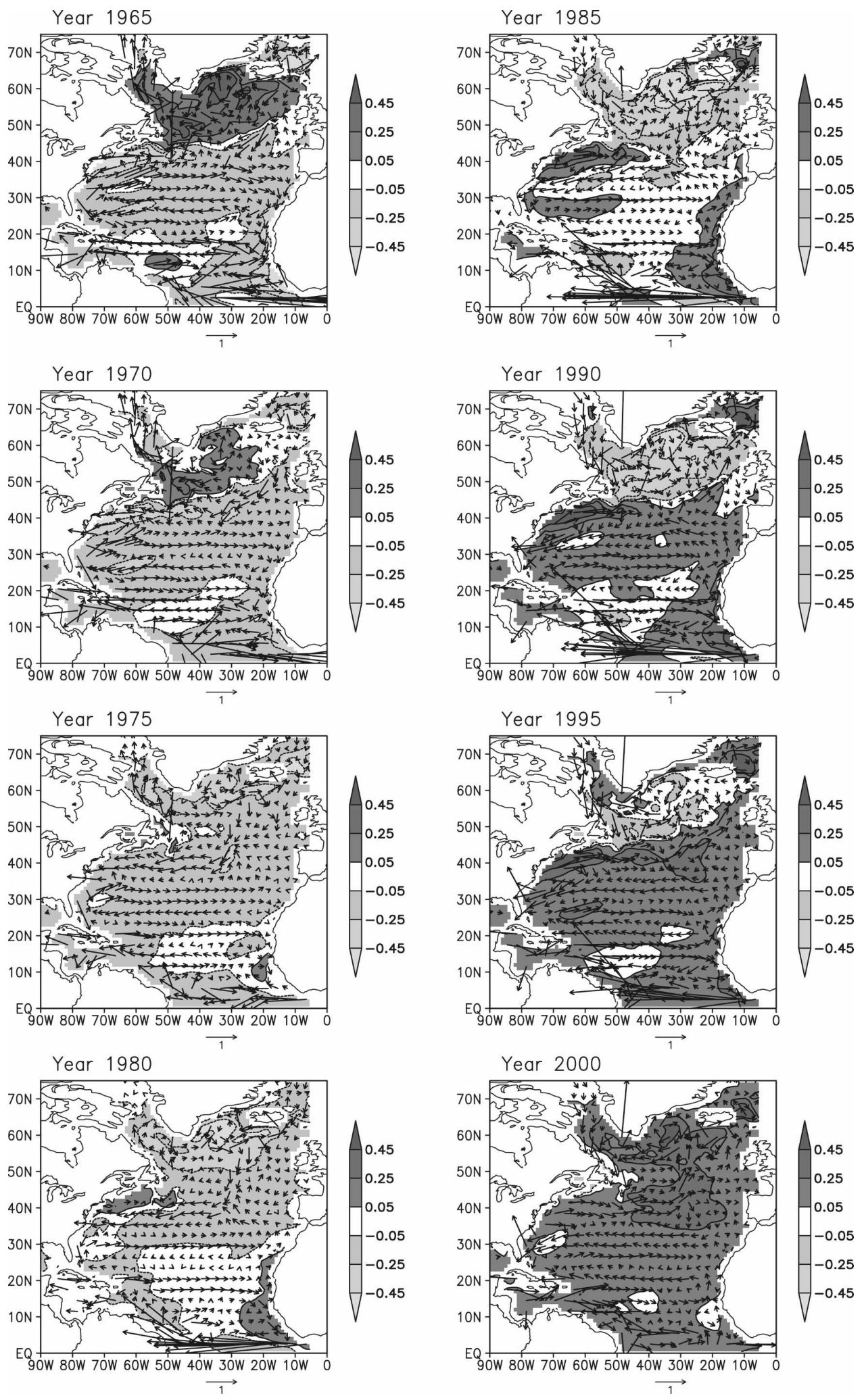

FIG. 9. ORCA05: snapshots of multidecadal MSSA component of North Atlantic SST (shades) and ocean currents (arrows) 1965-2000. Units are $\mathrm{K}$ and $\mathrm{cm} \mathrm{s}^{-1}$, respectively. 

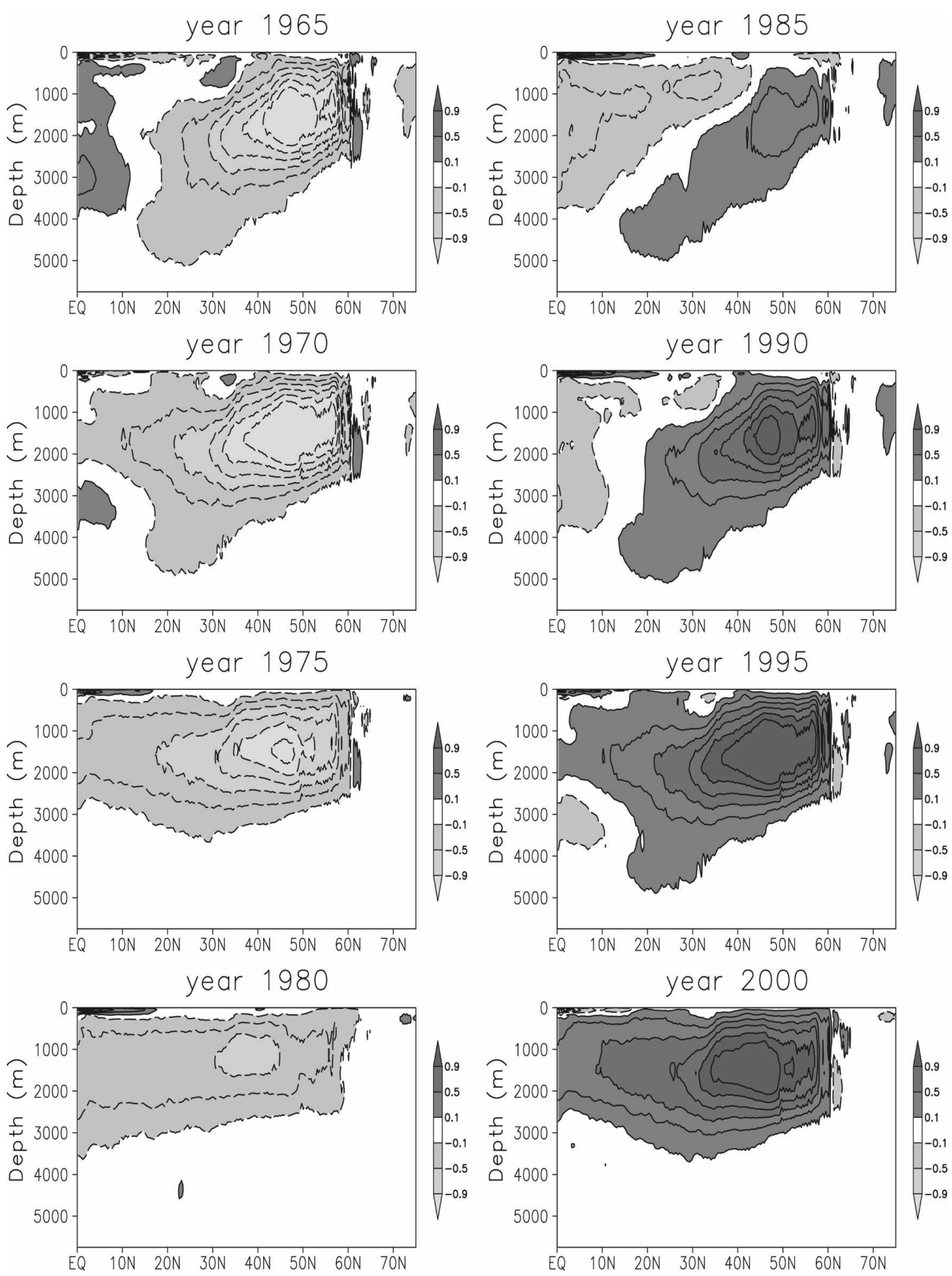

FIG. 10. ORCA05: snapshots of multidecadal MSSA component of Atlantic meridional streamfunction 1965-2000. Units are $\mathrm{Sv}\left(1 \mathrm{~Sv} \equiv 10^{6} \mathrm{~m}^{3} \mathrm{~s}^{-1}\right)$.

goes along with the onset of a cyclonic (anticyclonic) atmospheric circulation over the North Atlantic. Weakened (enhanced) westerlies and easterlies blow over the warm (cold) centers of the horseshoe structure in the subpolar and tropical North Atlantic. The atmospheric pattern of the decadal mode therefore displays NAOlike fluctuations, while the ocean shows SST anomalies consistent with their characteristic heat flux anomalies.

The wind stress anomalies induce a dynamical re- sponse in the ocean, which appears to be instantaneous, as shown in Fig. 14. A cyclonic (anticyclonic) circulation in the midlatitudinal upper ocean develops in phase with the positive (negative) wind stress curl anomalies. The anomalous cyclonic (anticyclonic) ocean circulation reduces (enhances) the heat transport of the Gulf Stream along the eastern coast of the United States, thus contributing to reinforce the negative (positive) SST anomalies there. The two poles of 


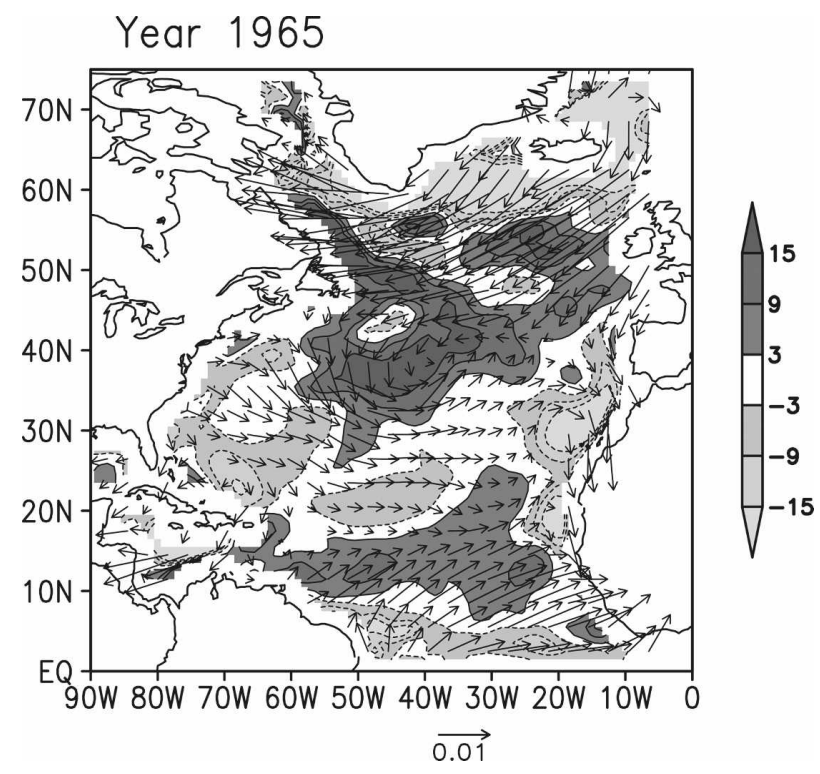

FIG. 11. ORCA05: multidecadal MSSA component of North Atlantic wind stress (arrows) and wind stress curl (shades) in year 1965. Units are $\mathrm{N} \mathrm{m}^{-2}$ and $10^{-9} \mathrm{~N} \mathrm{~m}^{-3}$, respectively.

the horseshoe pattern can also be strengthened by the anomalous ocean circulation via anomalous advection of the mean temperature gradient. The in-phase variation of wind stress, ocean currents, and SST anomalies in the decadal mode are emphasized in the cross correlations of Fig. 15: negative meridional currents at $38^{\circ} \mathrm{N}$ in the western Atlantic occur simultaneously with positive wind stress curl anomalies in the middle of the basin; the weaker meridional currents produce cold SST anomalies in the western Atlantic. In summary, the dynamical response of the ocean reinforces the decadal SST anomalies. This contrasts with results from different CGCM analyses that detect decadal coupled oscillatory modes in the North Atlantic that depend on the negative feedback provided by a delayed response of the wind-driven ocean circulation to atmospheric anomalies (Grötzner et al. 1998; Wu and Liu 2005). An immediate ocean response that contributes to the growth of SST anomalies is one of the key elements in the decadal oscillation found by EG03 in their hybrid coupled model simulation. They attribute the ocean's quick reaction in their simulation to the topographic Sverdrup response described by Eden and Willebrand (2001).

Looking for the negative feedback responsible for the switching of the oscillation's phase, we turn our attention to the overturning circulation in the North Atlantic, which is the agent operating the transition in the decadal oscillation of EG03. Figure 16 illustrates the decadal phase composite for the North Atlantic me- ridional streamfunction. A relatively shallow pattern of two cells with opposite signs, extending respectively poleward and equatorward from around $40^{\circ} \mathrm{N}$, forms between stages of strongest SST anomalies of different signs. Starting at phase 2, for instance, corresponding to warmest horseshoe and coldest western Atlantic SST anomalies (Fig. 12), we find the two-cell overturning pattern is developed about $1 \mathrm{yr}$ later (in phase 3 ). Its structure indicates there is anomalous horizontal divergence and upwelling in the upper subpolar and tropical North Atlantic, damping the positive SST anomalies of the horseshoe pattern, and anomalous horizontal convergence and downwelling in the midlatitudes, weakening the cold SST anomalies there. This overturning pattern persists for about $3 \mathrm{yr}$, changing the sign of the SST anomalies and progressively diminishing its amplitude. It disappears at phase 6 , when coldest horseshoe and warmest western Atlantic SST anomalies are reached (Fig. 12), and reverses its sign afterward. To highlight the phase quadrature relationship between the two-cell overturning pattern and the decadal SST structure, we compute two indices from the simulated data, keeping exclusively the variability associated with the decadal mode. The average SST anomaly in $\left(30^{\circ}\right.$ $\left.43^{\circ} \mathrm{N}, 70^{\circ}-50^{\circ} \mathrm{W}\right)$ monitors the SST pattern. For the overturning, we calculate a rough indicator of the twocell pattern by subtracting the value of the meridional streamfunction at $55^{\circ} \mathrm{N}$ from the one at $30^{\circ} \mathrm{N}$, at a depth of about $600 \mathrm{~m}$. The cross-correlation function of these indices is shown in Fig. 15, with the SST index leading for positive lags.

Overall, the simulated quasi-decadal SST oscillation, which satisfactorily represents its observed counterpart, appears to arise from the mechanism described in EG03, with the quick response of the oceanic currents to the changing wind stress exerting a positive impact on the development of the SST anomalies, and the delayed response of the North Atlantic overturning circulation providing the negative feedback required for the phase transition. The oscillation in the model of EG03 depends on the coupling of a tripolar SST pattern with NAO-related heat and momentum fluxes from the atmosphere. We cannot investigate the issue of the coupled or uncoupled nature of the quasi-decadal oscillation in our forced ocean simulation, but it may be worthy to note that, when MSSA is applied to the zonal wind stress only, eigenvalues 4 and 5 form a quasidecadal oscillatory pair with the same NAO-like pattern described above for the joint analysis. Figure 17 depicts the quasi-decadal reconstruction of a zonal wind stress index computed as the difference of anomalies over $\left(10^{\circ}-30^{\circ} \mathrm{N}, 60^{\circ}-20^{\circ} \mathrm{W}\right)$ minus those over $\left(40^{\circ}-\right.$ $\left.60^{\circ} \mathrm{N}, 50^{\circ}-10^{\circ} \mathrm{W}\right)$. It follows closely the evolution of the 
Phase 1

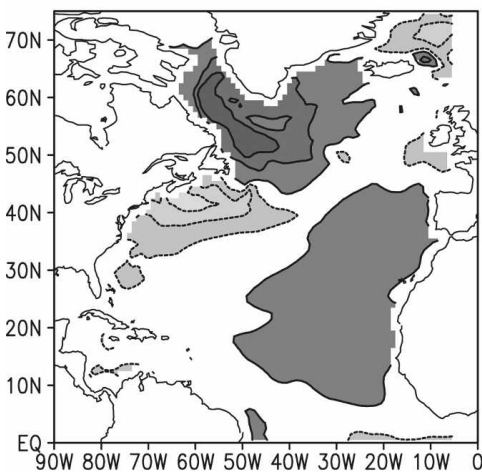

Phase 2

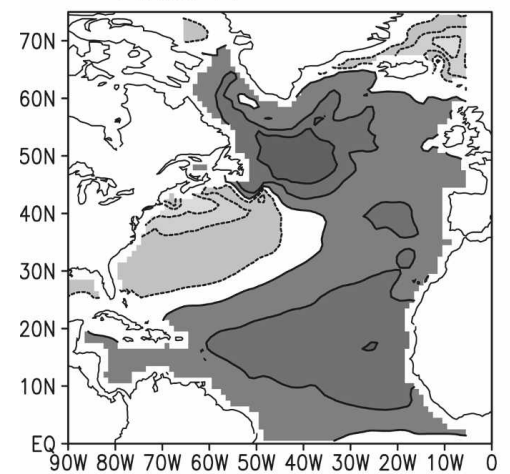
Phase 3

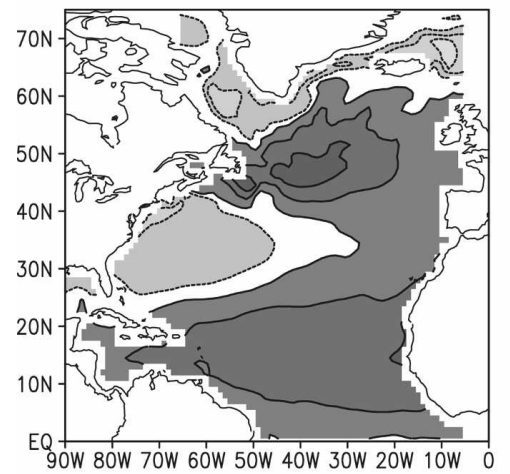
Phase 4

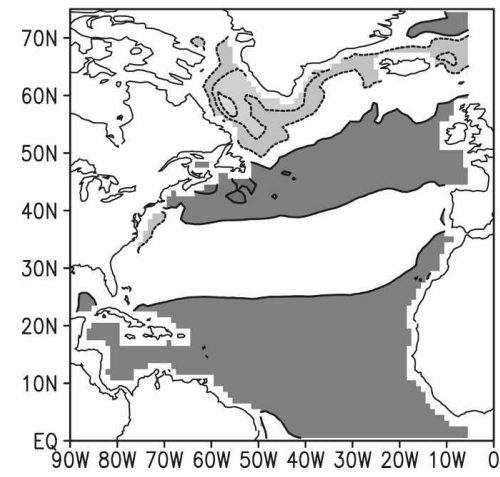

Phase 5

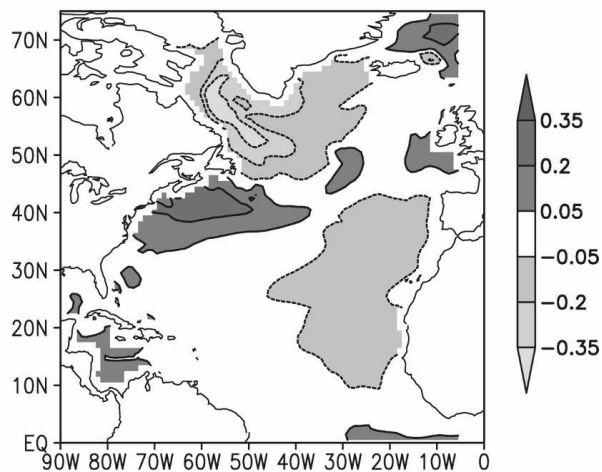

Phase 6

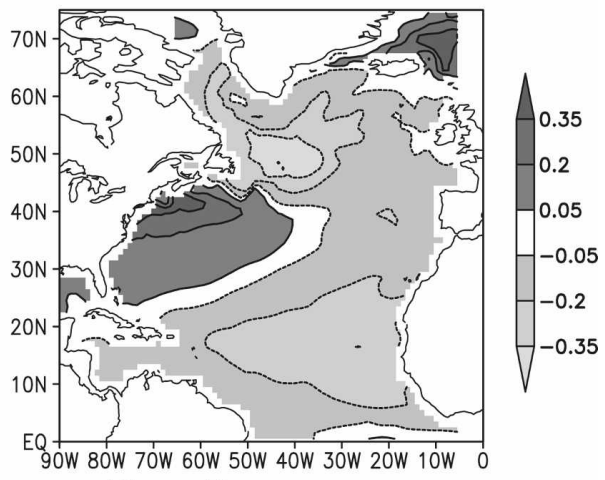
Phase 7

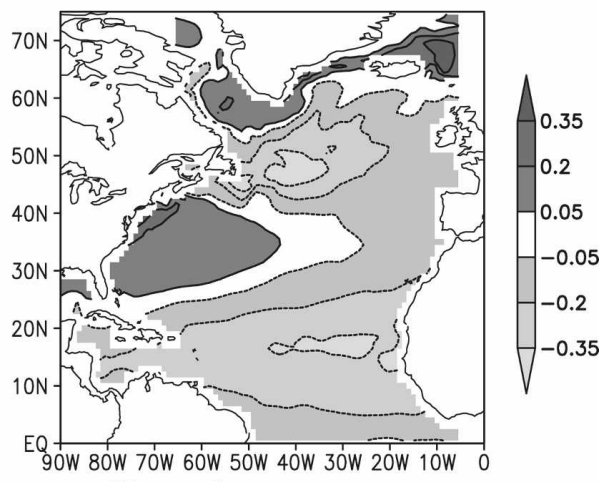
Phase 8

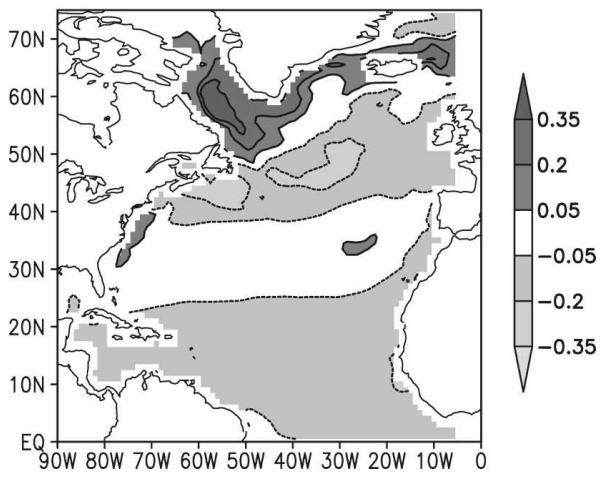

FIG. 12. ORCA05: phase composite of quasi-decadal MSSA component of North Atlantic SSTA (K). Consecutive phases are about $1 \mathrm{yr}$ apart. 
Phase 1

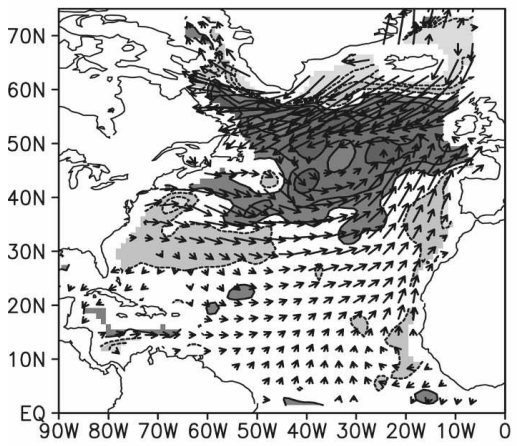

$\overrightarrow{0.01}$

Phase 2

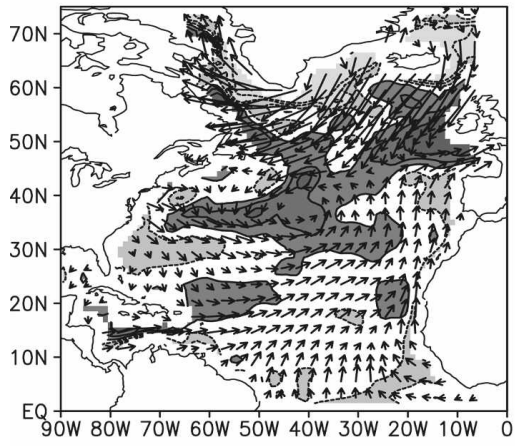

$\overrightarrow{0.01}$

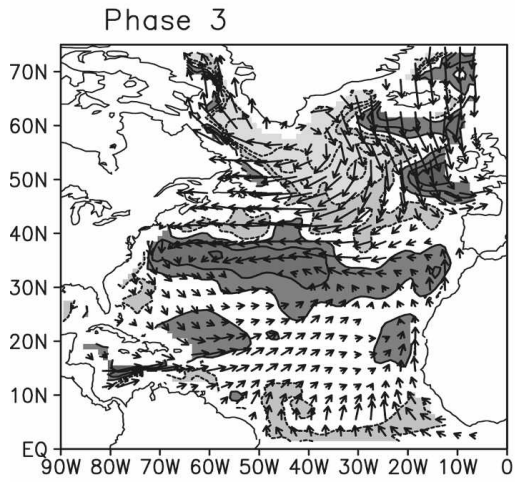

$\overrightarrow{0.01}$

Phase 4

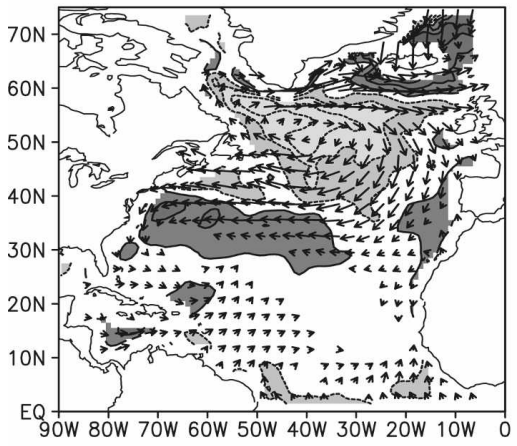

$\overrightarrow{0.01}$
Phase 5

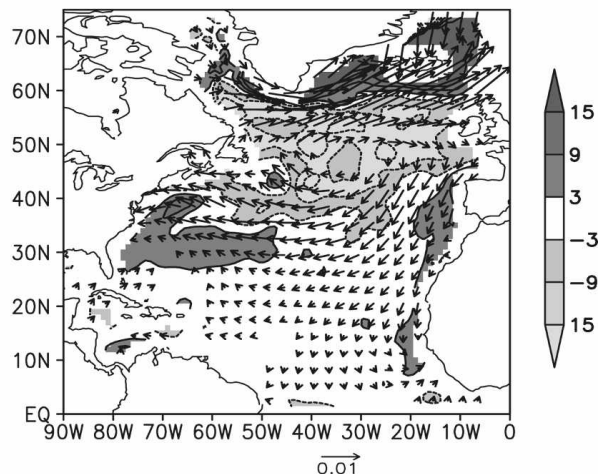

Phase 6

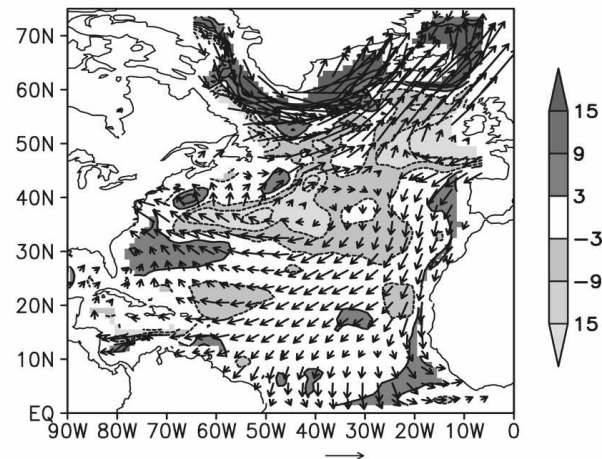

$\overrightarrow{0.01}$

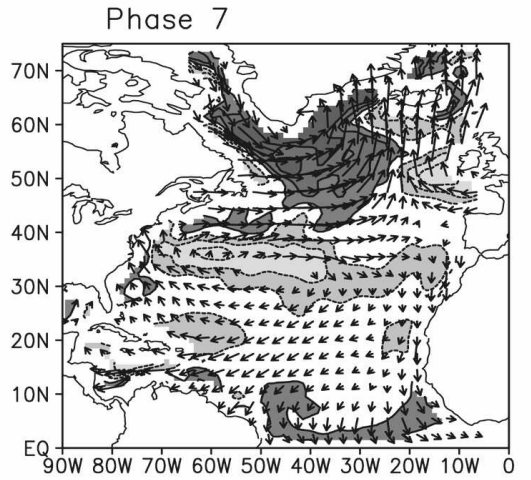

$\overrightarrow{0.01}$

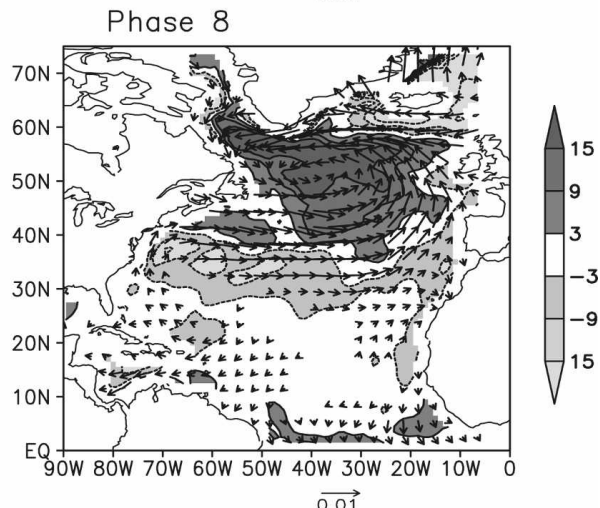

FIG. 13. ORCA05: phase composite of quasi-decadal MSSA component of wind stress (arrows) and wind stress curl (shades). Units are $\mathrm{N} \mathrm{m}^{-2}$ and $10^{-9} \mathrm{~N} \mathrm{~m}^{-3}$, respectively. Consecutive phases are about 1 yr apart. 
Phase 1

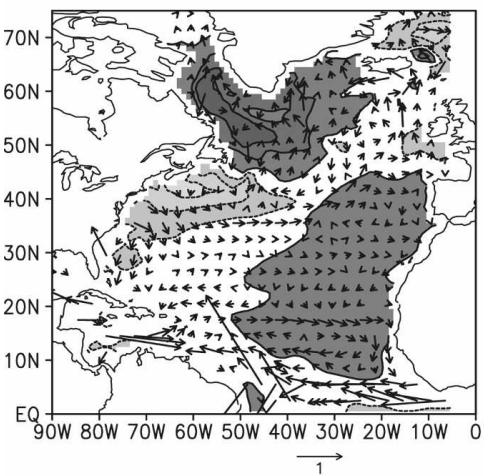

Phase 2

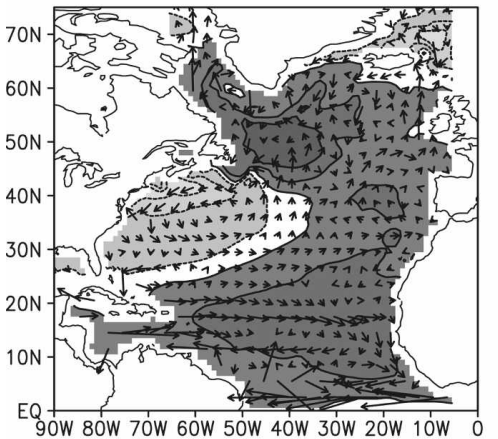

$\longrightarrow$

Phase 3

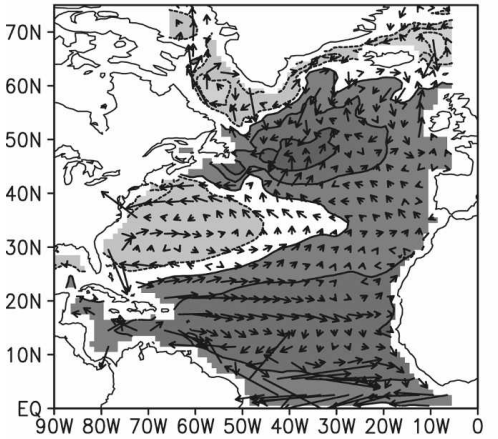

$\longrightarrow$

Phase 4

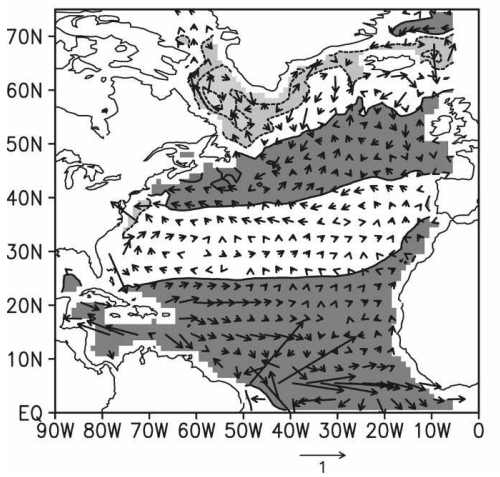

Phase 5

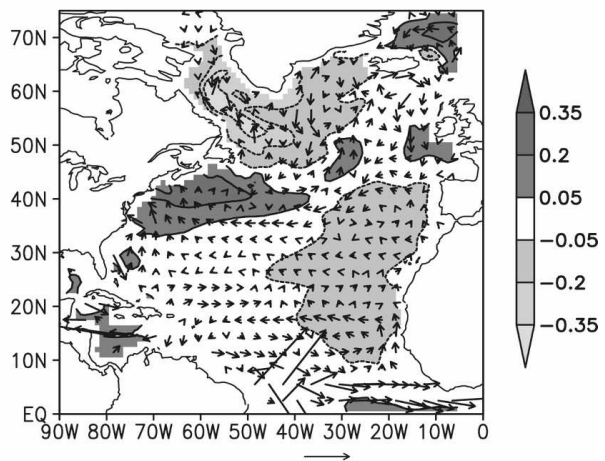

Phase 6

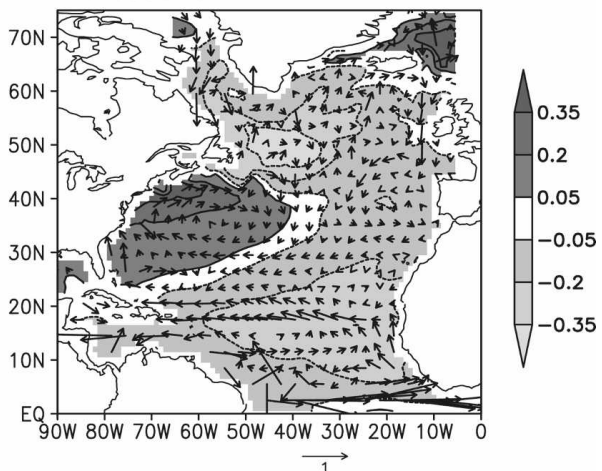

Phase 7

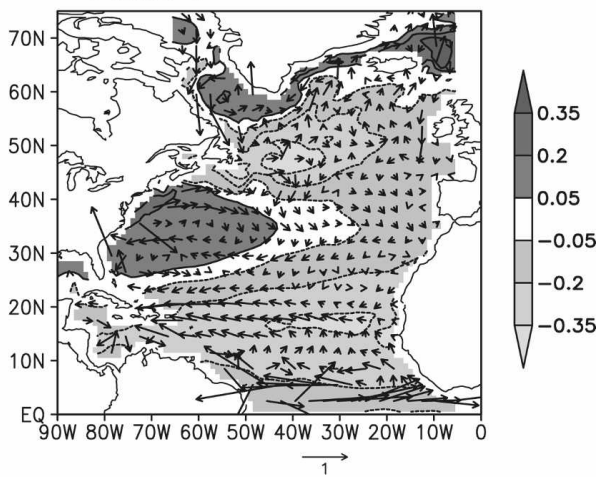

Phase 8

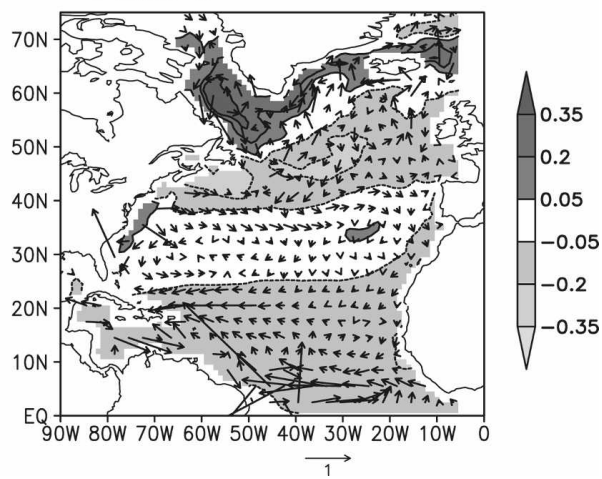

FIG. 14. ORCA05: phase composite of quasi-decadal MSSA component of upper-ocean currents (arrows) and SST (shades). Units are $\mathrm{cm} \mathrm{s}^{-1}$ and $\mathrm{K}$, respectively. Consecutive phases are about $1 \mathrm{yr}$ apart. 


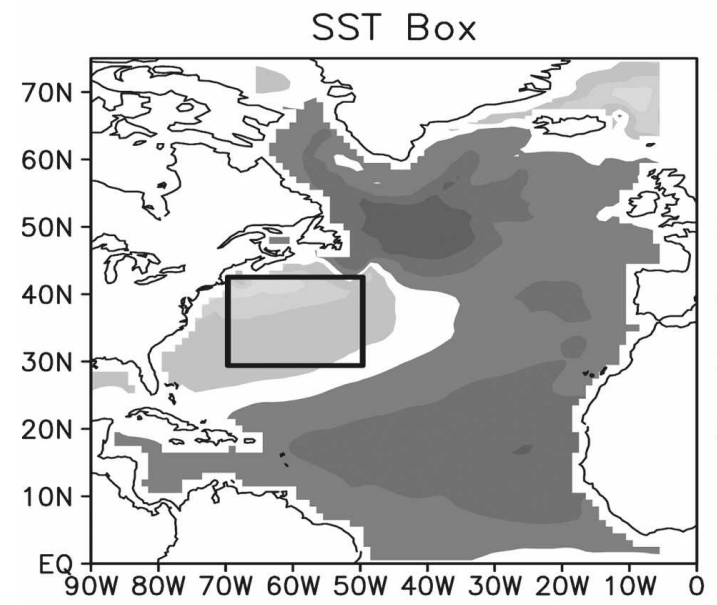

a)

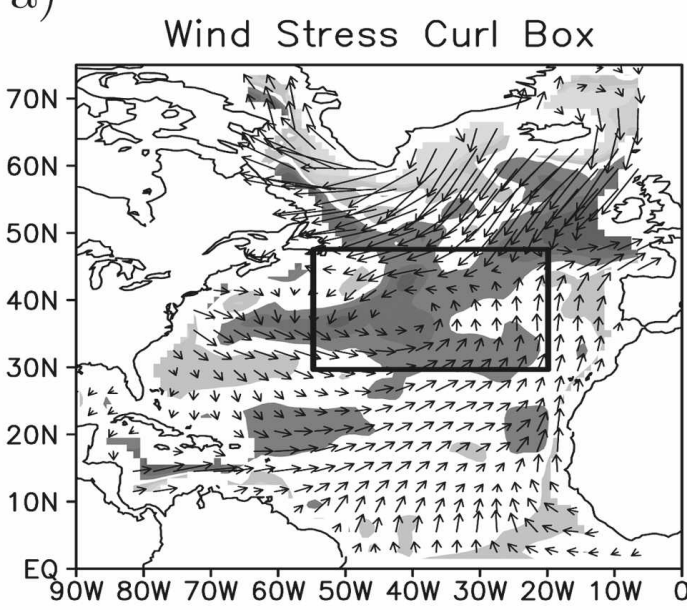

b)

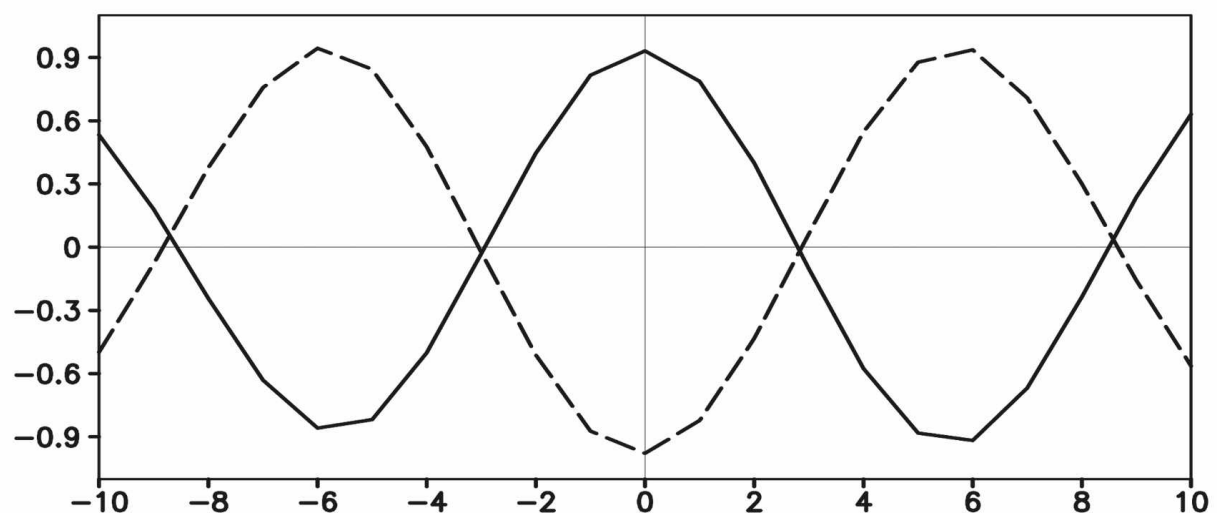

FIG. 15. Cross-correlation functions illustrative of the in-phase relationship of the decadal SST with the wind stress curl and the upper-ocean currents, and of their quadrature with the two-cell overturning pattern of Fig. 16. The indices used are decadal SST anomalies averaged over $\left(30^{\circ}-43^{\circ} \mathrm{N}, 70^{\circ}-50^{\circ} \mathrm{W}\right)$, decadal wind stress curl anomalies averaged over $\left(30^{\circ}-48^{\circ} \mathrm{N}, 55^{\circ}-20^{\circ} \mathrm{W}\right)$, anomalous meridional currents across $38^{\circ} \mathrm{N}$ between $75^{\circ}$ and $60^{\circ} \mathrm{W}$, and the meridional streamfunction difference between $30^{\circ}$ and $55^{\circ} \mathrm{N}$ (at a depth of $\sim 600 \mathrm{~m}$ ). (a) Averaging regions chosen for SST and wind stress curl (overlaid on the characteristic decadal SST and wind stress patterns); (b) cross correlation between the SST and the meridional currents indices (solid), and between the SST and the wind stress curl indices (dashed); and (c) cross correlation between the SST and the meridional streamfunction indices. SST leads for positive lags in all cross correlations.

quasi-decadal MSSA component of the 1958-2000 observed SST anomalies, also represented in Fig. 17 by the reconstruction of the average SST anomalies over $\left(40^{\circ}-60^{\circ} \mathrm{N}, 50^{\circ}-10^{\circ} \mathrm{W}\right)$. Furthermore, the regression (not shown) of sea level pressure anomalies from 1871 to 1998 on a North Atlantic SST index derived from the observed decadal mode also yields an NAO-like pattern, with positive NAO anomalies associated with cold SST in the subpolar and tropical North Atlantic. The presence of this decadal variability in the atmospheric data might be indicative of a sensitivity of the atmosphere to the underlying SST anomalies, in agreement with recent observational results (Frankignoul and Kestenare 2005). On this basis, we speculate our findings may be suggestive that atmosphere-ocean coupling is at the core of the quasi-decadal oscillation described here.

\section{Summary}

We have analyzed the dynamics of decadal-scale variations in the North Atlantic. Two modes are identified in observations and a model simulation: a multidecadal mode and a quasi-decadal mode. Our analyses indicate that the multidecadal mode can be regarded as 

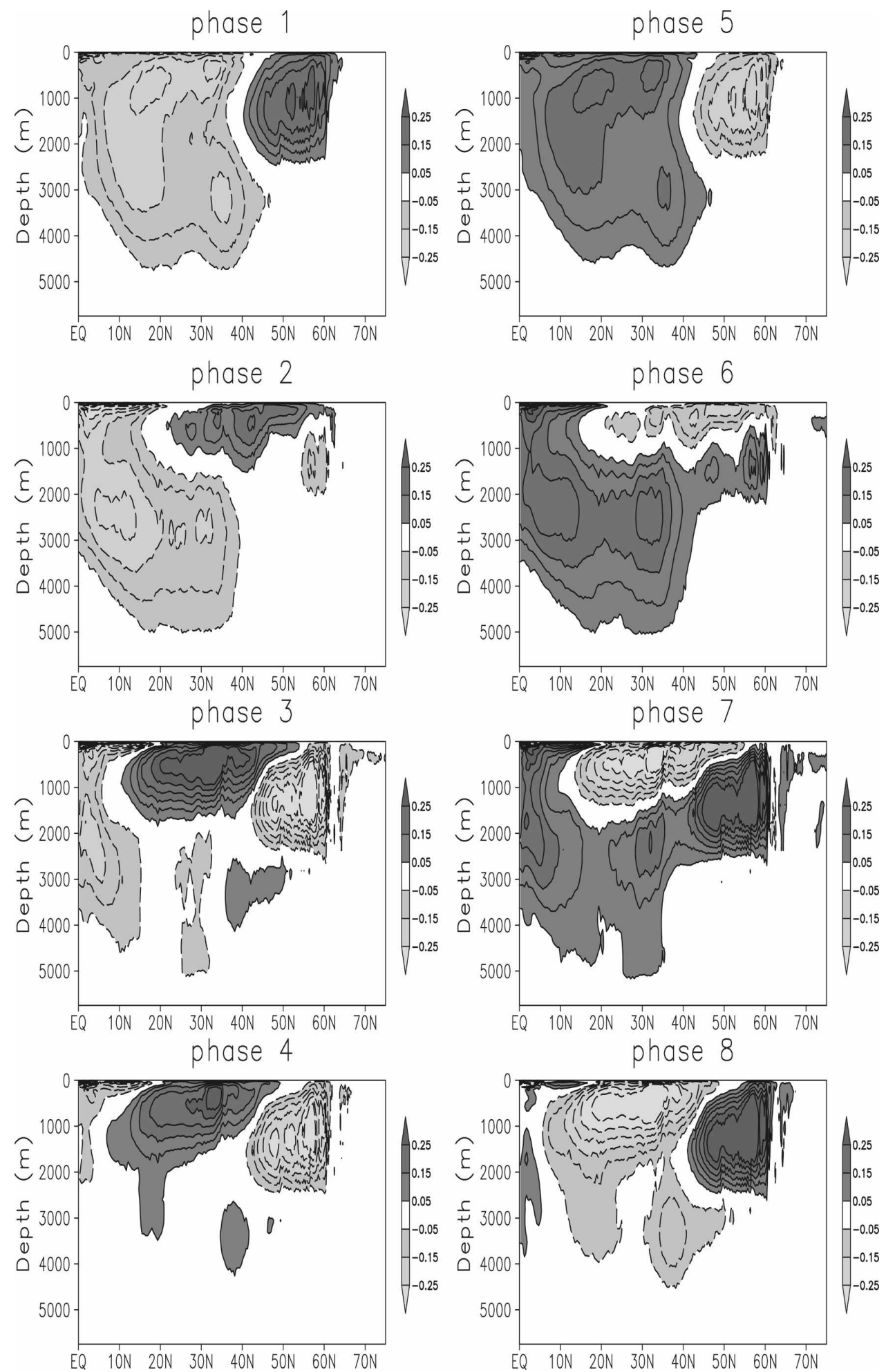

FIG. 16. ORCA05: phase composite of quasi-decadal MSSA component of Atlantic meridional streamfunction. Units are Sv. Consecutive phases are about 1 yr apart. 


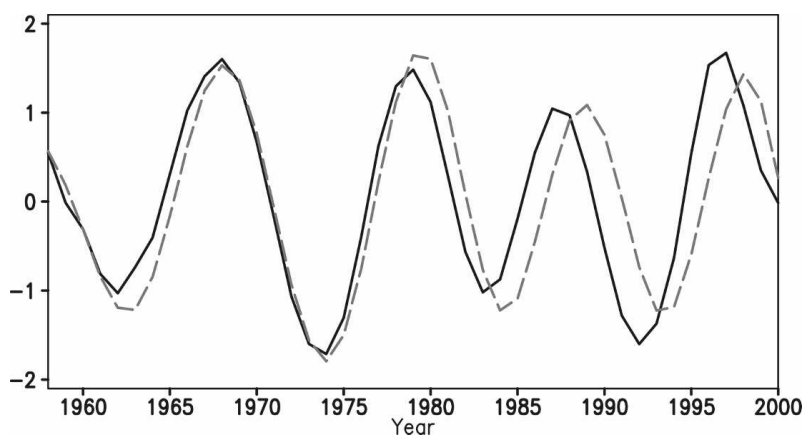

FIG. 17. Zonal wind stress index $\left(10^{\circ}-30^{\circ} \mathrm{N}, 60^{\circ}-20^{\circ} \mathrm{W}\right)-\left(40^{\circ}-\right.$ $\left.60^{\circ} \mathrm{N}, 50^{\circ}-10^{\circ} \mathrm{W}\right)$ reconstructed from the quasi-decadal MSSA component of North Atlantic zonal wind stress anomalies (black, solid). SST index $\left(40^{\circ}-60^{\circ} \mathrm{N}, 50^{\circ}-10^{\circ} \mathrm{W}\right)$ reconstructed from the quasi-decadal MSSA component of North Atlantic SST anomalies (gray, dashed). Both time series are normalized by their respective standard deviations.

the MOC response to the multidecadal forcing associated with the NAO. The multidecadal NAO fluctuations change the deep water formation in the Labrador Sea through anomalous surface heat fluxes, which leads with a lag of about a decade to an adjustment of the MOC. It remains controversial, however, what the forcing of the multidecadal NAO variations is. It should be noted as well that viable mechanisms for the generation of multidecadal North Atlantic SST anomalies other than low-frequency NAO forcing have been proposed and, despite the suggestive observational lagged correlation and the results here, we cannot decisively conclude as yet what the real mechanism is.

On the other hand, in the model used here, the quasidecadal mode involves both simultaneous and delayed feedbacks from the North Atlantic circulation response to the NAO. The wind-driven ocean circulation reinforces the SST anomalies and thus acts as a positive feedback, while the delayed negative feedback is provided by the MOC. The quasi-decadal mode, however, is strongly damped, so that it is not seen as a statistically significant peak in conventional spectra of either the NAO or North Atlantic SST. Yet, the two modes demonstrate how the dynamics of the MOC variability changes from decadal to multidecadal time scales. The different dynamics are expressed by the different SST anomaly patterns, the tripole, and the monopole, that prevail on quasi-decadal and multidecadal time scales, respectively. Furthermore, the multidecadal mode involves propagating SST anomalies, while the quasidecadal mode is stationary in terms of the SST anomalies.

Since good simulations of the North Atlantic SST anomalies during the last four decades of the past century have been achieved using ocean mixed layer mod- els forced by observed atmospheric variability (Seager et al. 2000), the relevance of the ocean dynamics in the quasi-decadal mode can be put to question. While there also exist indications that ocean dynamics plays a role in the observed SST fluctuations, particularly at the longer time scales (Visbeck et al. 2003), it must be noted that the interpretation given here is not contradictory with the decadal variations in atmospheric heat fluxes being responsible for a major part of the SST anomalies. The generation of such low-frequency atmospheric variability remains unexplained, though. The results of Walter and Graf (2002) that periods of higher quasi-decadal variability in the NAO are characterized by its stronger correlation with the North Atlantic SST, and weaker remote influences on the region, suggest a local origin. Our main contribution in this regard is to show that the decadal part of the observed atmospheric forcing can be associated in our simulation with ocean dynamics that has been shown to possess an inherent decadal time scale (EG03) and that is consistent with the stationary SST tripole characteristic of the observed decadal variability. Further study is required to assess the importance of this dynamics in the coupled system.

Concerning the predictability of the two modes, the multidecadal mode is more promising. Potentially useful predictability has been associated to it in recent studies (Latif et al. 2006a). Since it can be understood as the ocean's response to low-frequency forcing by the $\mathrm{NAO}$, its future time evolution may be determined by the past history of the NAO. Thus, ocean models can be forced by the observed boundary conditions, and these conditions can then be used subsequently to initialize coupled model forecasts. The predictability of the quasi-decadal mode is less clear. This mode seems to be strongly damped, so that it will be hard to beat persistence.

Acknowledgments. This work was supported by the Sonderforschungsbereich 460 of the German Science Foundation (DFG) and by the European Union Projects ENSEMBLES and DYNAMITE. F. Álvarez was supported by the University of Alcala through the Vicerrectorate of Research's and the "José Castillejo" Mobility Grants. Useful comments from Dr. N. Keenlyside are gratefully acknowledged.

\section{REFERENCES}

Allen, M. R., and A. W. Robertson, 1996: Distinguishing modulated oscillations from coloured noise in multivariate datasets. Climate Dyn., 12, 775-784.

Barnier, B., and Coauthors, 2005: Impact of partial steps and momentum advection schemes in a global ocean circulation model at eddy-permitting resolution. Ocean Dyn., 56, 543567. 
Biastoch, A., C. W. Böning, J. Getzlaff, J.-M. Molines, and G. Madec, 2008: Causes of interannual-decadal variability in the meridional overturning circulation of the midlatitude North Atlantic. J. Climate, in press.

Cayan, D., 1992: Latent and sensible heat flux anomalies over the northern oceans: Driving the sea surface temperature. $J$. Phys. Oceanogr., 22, 859-881.

Czaja, A., and J. Marshall, 2001: Observations of atmosphereocean coupling in the North Atlantic. Quart. J. Roy. Meteor. Soc., 127, 1893-1916.

Deser, C., and M. L. Blackmon, 1993: Surface climate variations over the North Atlantic Ocean during winter: 1900-1989. J. Climate, 6, 1743-1753.

Eden, C., and T. Jung, 2001: North Atlantic interdecadal variability: Oceanic response to the North Atlantic Oscillation (1865-1997). J. Climate, 14, 676-691.

— , and J. Willebrand, 2001: Mechanism of interannual to decadal variability of the North Atlantic circulation. J. Climate, 14, 2266-2280.

— the North Atlantic Climate System. J. Climate, 16, 4043-4060.

Frankignoul, C., and E. Kestenare, 2005: Observed Atlantic SST anomaly impact on the NAO: An update. J. Climate, 18, 4089-4094.

_ _ P. Muller, and E. Zorita, 1997: A simple model of the decadal response of the ocean to stochastic wind forcing. $J$. Phys. Oceanogr., 27, 1533-1546.

Gent, P. R., and J. C. McWilliams, 1990: Isopycnal mixing in ocean circulation models. J. Phys. Oceanogr., 20, 150-155.

Ghil, M., and Coauthors, 2002: Advanced spectral methods for climatic time series. Rev. Geophys., 40, 1003, doi:10.1029/ 2000RG000092.

Grötzner, A., M. Latif, and T. P. Barnett, 1998: A decadal climate cycle in the North Atlantic Ocean as simulated by the ECHO coupled GCM. J. Climate, 18, 831-847.

Hansen, D. V., and H. F. Bezdek, 1996: On the nature of decadal anomalies in North Atlantic sea surface temperature. J. Geophys. Res., 101 (C4), 8749-8758.

Karoly, D. J., and Q. Wu, 2005: Detection of regional surface temperature trends. J. Climate, 18, 4337-4343.

Knight, J. R., R. J. Allan, C. K. Folland, M. Vellinga, and M. E. Mann, 2005: A signature of persistent natural thermohaline circulation cycles in observed climate. Geophys. Res. Lett., 32, L20708, doi:10.1029/2005GL024233.

_ C. K. Folland, and A. A. Scaife, 2006: Climate impacts of the Atlantic Multidecadal Oscillation. Geophys. Res. Lett., 33, L17706, doi:10.1029/2006GL026242.

Krahmann, G., M. Visbeck, and G. Reverdin, 2001: Formation and propagation of temperature anomalies along the North Atlantic Current. J. Phys. Oceanogr., 31, 1287-1303.

Kushnir, Y., 1994: Interdecadal variations in North Atlantic sea surface temperature and associated atmospheric conditions. J. Climate, 7, 141-157.

Large, W. G., and S. G. Yeager, 2004: Diurnal to decadal global forcing for ocean and sea-ice models: The data sets and flux climatologies. NCAR Tech. Note NCAR/TN-460+STR, 111 pp.

Latif, M., and Coauthors, 2004: Reconstructing, monitoring, and predicting multidecadal-scale changes in the North Atlantic thermohaline circulation with sea surface temperature. J. Climate, 17, 1605-1614.

_, M. Collins, H. Pohlmann, and N. Keenlyside, 2006a: A review of predictability studies of Atlantic sector climate on decadal time scales. J. Climate, 19, 5971-5987.

_ C. W. Böning, J. Willebrand, A. Biastoch, J. Dengg, N. Keenlyside, U. Schwekendieck, and G. Madec, 2006b: Is the thermohaline circulation changing? J. Climate, 18, 4631-4637.

Madec, G., P. Delecluse, M. Imbard, and C. Levy, 1999: OPA 8.1 General circulation model reference manual. Pierre-Simon Laplace des Sciences de l'Environment Global Tech. Note $11,91 \mathrm{pp}$.

Moron, V., R. Vautaurd, and M. Ghil, 1998: Trends, interdecadal and interannual oscillations in global sea-surface temperatures. Climate Dyn., 14, 545-569.

Rayner, N. A., D. E. Parker, E. B. Horton, C. K. Folland, L. V. Alexander, D. P. Rowell, E. C. Kent, and A. Kaplan, 2003: Global analyses of sea surface temperature, sea ice, and night marine air temperatures since the late nineteenth century. $J$. Geophys. Res., 108, 4407, doi:10.1029/2002JD002670.

Saravanan, R., and J. C. McWilliams, 1998: Advective oceanatmosphere interaction: An analytical stochastic model with implications for decadal variability. J. Climate, 11, 165-188.

Seager, R., Y. Kushnir, M. Visbeck, N. Naik, J. Miller, G. Krahmann, and H. Cullen, 2000: Causes of Atlantic Ocean climate variability between 1958 and 1998. J. Climate, 13, 2845-2862.

Sutton, R. T., and M. R. Allen, 1997: Decadal predictability of North Atlantic sea surface temperature and climate. Nature, 388, 563-567.

, and D. L. R. Hodson, 2005: Atlantic Ocean forcing of North American and European summer climate. Science, 309, 115118.

Trenberth, K. E., and D. J. Shea, 2006: Atlantic hurricanes and natural variability in 2005. Geophys. Res. Lett., 33, L12704, doi:10.1029/2006GL026894.

Visbeck, M., E. Chassignet, R. Curry, T. Delworth, B. Dickson, and G. Krahmann, 2003: The ocean's response to North Atlantic Oscillation variability. The North Atlantic Oscillation: Climatic Significance and Environmental Impact, Geophys. Monogr., Vol. 134, Amer. Geophys. Union, 113-146.

Walter, K., and H.-F. Graf, 2002: On the changing nature of the regional connection between the North Atlantic Oscillation and sea surface temperature. J. Geophys. Res., 107 (D17), 4338, doi:10.1029/2001JD000850.

Wu, L., and Z. Liu, 2005: North Atlantic decadal variability: Airsea coupling, oceanic memory, and potential Northern Hemisphere resonance. J. Climate, 18, 331-349.

Zhang, R., and T. L. Delworth, 2006: Impact of Atlantic multidecadal oscillations on India/Sahel rainfall and Atlantic hurricanes. Geophys. Res. Lett., 33, L17712, doi:10.1029/ 2006 GL026267. 